\title{
Exercise for osteoarthritis of the hip (Review)
}

\author{
Fransen M, McConnell S, Hernandez-Molina G, Reichenbach S
}

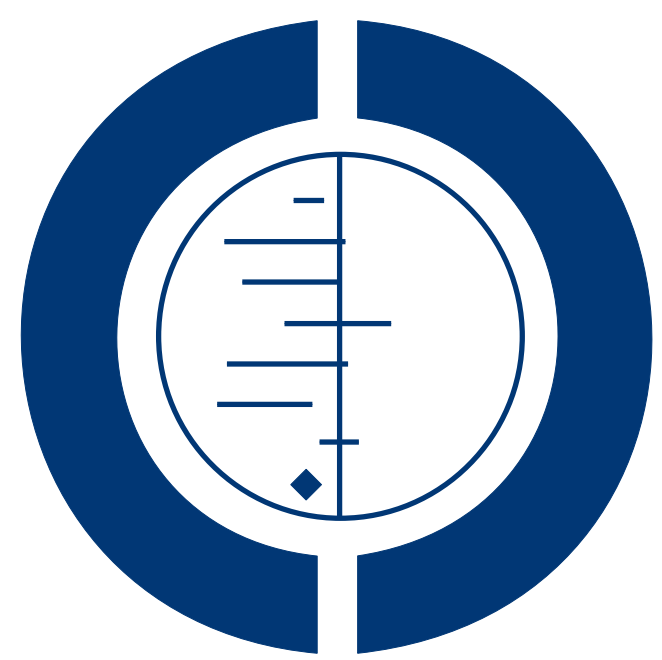

\section{THE COCHRANE COLLABORATION $^{\circledR}$}

This is a reprint of a Cochrane review, prepared and maintained by The Cochrane Collaboration and published in The Cochrane Library 2014, Issue 4

http://www.thecochranelibrary.com

\section{WILEY}


TABLE OF CONTENTS

HEADER

ABSTRACT

PLAIN LANGUAGE SUMMARY

OBJECTIVES

METHODS . . . . . . . . . . . . . . . . . . . . . . . . . . . . . . . . . . 6

RESULTS . . . . . . . . . . . . . . . . . . . . . . . . . . . . . . . . . . . . 8

Figure 1. . . . . . . . . . . . . . . . . . . . . . . . . . . . . . . . . . . . 10

Figure 2. . . . . . . . . . . . . . . . . . . . . . . . . . . . . . . 12

Figure 3. . . . . . . . . . . . . . . . . . . . . . . . . . . . . . . . . . 14

Figure 4. . . . . . . . . . . . . . . . . . . . . . . . . . . . . . . . . . . . . . 15

Figure 5. . . . . . . . . . . . . . . . . . . . . . . . . . . . . . . . . . 16

Figure 6. . . . . . . . . . . . . . . . . . . . . . . . . . . . . . . . . . . . 16

ADDITIONAL SUMMARY OF FINDINGS . . . . . . . . . . . . . . . . . . . . . . . . . . . . . . . . 17

DISCUSSION . . . . . . . . . . . . . . . . . . . . . . . . . . . . . . . . . . . . . 20

AUTHORS' CONCLUSIONS . . . . . . . . . . . . . . . . . . . . . . . . . . . . . . . . 21

ACKNOWLEDGEMENTS . . . . . . . . . . . . . . . . . . . . . . . . . . . . . . . . . 21

REFERENCES . . . . . . . . . . . . . . . . . . . . . . . . . . . . . . . . . . . . . . 21

CHARACTERISTICS OF STUDIES . . . . . . . . . . . . . . . . . . . . . . . . . . . . . . . . . . . . . . . .

DATA AND ANALYSES . . . . . . . . . . . . . . . . . . . . . . . . . . . . . . . . . . . . 38

Analysis 1.1. Comparison 1 Immediate post treatment, Outcome 1 Pain. . . . . . . . . . . . . . . . . 39

Analysis 1.2. Comparison 1 Immediate post treatment, Outcome 2 Physical function. . . . . . . . . . . . . 40

Analysis 1.3. Comparison 1 Immediate post treatment, Outcome 3 Quality of life. . . . . . . . . . . . . 41

Analysis 1.4. Comparison 1 Immediate post treatment, Outcome 4 Study withdrawals. . . . . . . . . . . . 42

Analysis 2.1. Comparison 2 Sustainability (three to six months), Outcome 1 Pain. . . . . . . . . . . . . . . . . 43

Analysis 2.2. Comparison 2 Sustainability (three to six months), Outcome 2 Physical function. . . . . . . . . . . 44

Analysis 3.1. Comparison 3 Hip osteoarthritis (OA) versus hip/knee OA studies, Outcome 1 Pain post treatment. $\quad .45$

Analysis 3.2. Comparison 3 Hip osteoarthritis (OA) versus hip/knee OA studies, Outcome 2 Physical function post treatment. . . . . . . . . . . . . . . . . . . . . . . . . . 4 46

APPENDICES . . . . . . . . . . . . . . . . . . . . . . . . . . . . . . . . . . . . . 46

WHAT'S NEW . . . . . . . . . . . . . . . . . . . . . . . . . . . . . . . . . . . . . 50

HISTORY . . . . . . . . . . . . . . . . . . . . . . . . . . . . . . . . . . . . . . . . . . . 51

CONTRIBUTIONS OF AUTHORS . . . . . . . . . . . . . . . . . . . . . . . . . . . . . . . . . . . . 51

DECLARATIONS OF INTEREST . . . . . . . . . . . . . . . . . . . . . . . . . . . . . . . . . . . . . . .

SOURCES OF SUPPORT . . . . . . . . . . . . . . . . . . . . . . . . . . . . . . . . . . . . 52

DIFFERENCES BETWEEN PROTOCOL AND REVIEW . . . . . . . . . . . . . . . . . . . . . . 52

INDEX TERMS . . . . . . . . . . . . . . . . . . . . . . . . . . . . . . . . . . 52

Exercise for osteoarthritis of the hip (Review)

Copyright $\odot 2014$ The Cochrane Collaboration. Published by John Wiley \& Sons, Ltd. 


\title{
[Intervention Review] \\ Exercise for osteoarthritis of the hip
}

\author{
Marlene Fransen $^{1}$, Sara McConnell ${ }^{2}$, Gabriela Hernandez-Molina ${ }^{3}$, Stephan Reichenbach ${ }^{4}$ \\ ${ }^{1}$ Faculty of Health Sciences, University of Sydney, Sydney, Australia. ${ }^{2}$ Department of Medicine, St Joseph's Health Care Centre, \\ Toronto, Canada. ${ }^{3}$ Immunology and Rheumatology, Instituto Nacional de Ciencias Médicas y Nutrición Salvador Zubirán, Mexico \\ city, Mexico. ${ }^{4}$ Department for Rheumatology, Clinical Immunology, and Allergology, University Hospital, Bern, Switzerland \\ Contact address: Marlene Fransen, Faculty of Health Sciences, University of Sydney, Room 0212, Cumberland Campus C42, Sydney, \\ New South Wales, 1825, Australia. marlene.fransen@sydney.edu.au. \\ Editorial group: Cochrane Musculoskeletal Group. \\ Publication status and date: New search for studies and content updated (conclusions changed), published in Issue 4, 2014. \\ Review content assessed as up-to-date: 9 May 2013.
}

Citation: Fransen M, McConnell S, Hernandez-Molina G, Reichenbach S. Exercise for osteoarthritis of the hip. Cochrane Database of Systematic Reviews 2014, Issue 4. Art. No.: CD007912. DOI: 10.1002/14651858.CD007912.pub2.

Copyright (C) 2014 The Cochrane Collaboration. Published by John Wiley \& Sons, Ltd.

\begin{abstract}
A B S T R A C T

\section{Background}

Current international treatment guidelines recommending therapeutic exercise for people with symptomatic hip osteoarthritis (OA) report are based on limited evidence.
\end{abstract}

\section{Objectives}

To determine whether land-based therapeutic exercise is beneficial for people with hip OA in terms of reduced joint pain and improved physical function and quality of life.

\section{Search methods}

We searched five databases from inception up to February 2013.

\section{Selection criteria}

All randomised controlled trials (RCTs) recruiting people with hip OA and comparing some form of land-based therapeutic exercise (as opposed to exercises conducted in water) with a non-exercise group.

\section{Data collection and analysis}

Four review authors independently selected studies for inclusion. We resolved disagreements through consensus. Two review authors independently extracted data, assessed risk of bias and the quality of the body of evidence for each outcome using the GRADE approach. We conducted analyses on continuous outcomes (pain, physical function and quality of life) and dichotomous outcomes (proportion of study withdrawals).

\section{Main results}

We considered that seven of the 10 included RCTs had a low risk of bias. However, the results may be vulnerable to performance and detection bias as none of the RCTs were able to blind participants to treatment allocation and, while most RCTs reported blinded outcome assessment, pain, physical function and quality of life were participant self reported. One of the 10 RCTs was only reported as a conference abstract and did not provide sufficient data for the evaluation of bias risk.

High-quality evidence from nine trials (549 participants) indicated that exercise reduced pain (standardised mean difference (SMD) $0.38,95 \%$ confidence interval (CI) -0.55 to -0.20 ) and improved physical function (SMD $-0.38,95 \%$ CI -0.54 to -0.05 ) immediately

Exercise for osteoarthritis of the hip (Review)

Copyright $\odot 2014$ The Cochrane Collaboration. Published by John Wiley \& Sons, Ltd. 
after treatment. Pain and physical function were estimated to be 29 points on a 0 - to 100 -point scale ( 0 was no pain or loss of physical function) in the control group; exercise reduced pain by an equivalent of 8 points (95\% CI 4 to 11 points; number needed to treat for an additional beneficial outcome (NNTB) 6) and improved physical function by an equivalent of 7 points (95\% CI 1 to 12 points; NNTB 6). Only three small studies (183 participants) evaluated quality of life, with overall low quality evidence, with no benefit of exercise demonstrated (SMD - 0.07, 95\% CI - 0.23 to 0.36 ). Quality of life was estimated to be 50 points on a norm-based mean (standard deviation (SD)) score of 50 (10) in the general population in the control group; exercise improved quality of life by 0 points. Moderatequality evidence from seven trials (715 participants) indicated an increased likelihood of withdrawal from the exercise allocation (event rate $6 \%$ ) compared with the control group (event rate 3\%), but this difference was not significant (risk difference $1 \%$; $95 \%$ CI $-1 \%$ to $4 \%$ ). Of the five studies reporting adverse events, each study reported only one or two events and all were related to increased pain attributed to the exercise programme.

The reduction in pain was sustained at least three to six months after ceasing monitored treatment (five RCTs, 391 participants): pain (SMD - $0.38,95 \%$ CI -0.58 to -0.18). Pain was estimated to be 29 points on a 0 - to 100 -point scale (0 was no pain) in the control group, the improvement in pain translated to a sustained reduction in pain intensity of 8 points ( $95 \%$ CI 4 to 12 points) compared with the control group ( 0 to 100 scale). The improvement in physical function was also sustained (five RCTs, 367 participants): physical function (SMD - $0.37,95 \%$ CI -0.57 to -0.16). Physical function was estimated to be 24 points on a 0 - to 100 -point scale (0 was no loss of physical function) in the control group, the improvement translated to a mean of 7 points (95\% CI 4 to 13 ) compared with the control group.

Only five of the 10 RCTs exclusively recruited people with symptomatic hip OA (419 participants). There was no significant difference in pain or physical function outcomes compared with five studies recruiting participants with hip or knee OA (130 participants).

\section{Authors' conclusions}

Pooling the results of these 10 RCTs demonstrated that land-based therapeutic exercise programmes can reduce pain and improve physical function among people with symptomatic hip OA.

\section{PLAIN LANGUAGE SUMMARY}

\section{Exercise for osteoarthritis of the hip}

\section{Background - what is OA of the hip and what is exercise?}

OA is a disease of the joints, such as your hip. When the joint loses cartilage, the bone grows to try to repair the damage. However, instead of making things better, the bone grows abnormally and makes things worse. For example, the bone can become misshapen and make the joint painful and unstable. Doctors used to think that osteoarthritis (OA) simply resulted in thinning of the cartilage. However, it is now known that $\mathrm{OA}$ is a disease of the whole joint.

OA is one of the most common forms of arthritis and affects men and women equally. OA is one of the main causes of disability as people grow older.

Exercise can be any activity that enhances or maintains muscle strength, physical fitness and overall health. People exercise for many different reasons including weight loss, strengthening muscles and to relieve the symptoms of OA.

\section{Study characteristics}

This summary of an update of a Cochrane review presents what we know from research about the effect of exercise for people with OA of the hip. After searching for all relevant studies up to February 2013, we included five new studies since the last version of the review, giving 10 studies (549 participants) with mostly mild-to-moderate symptomatic hip OA, alone or with knee OA. Except for one study where participants enrolled in a tai chi programme, all other participants underwent land-based exercise programmes consisting of traditional muscle strengthening, functional training and aerobic fitness programmes, either individually supervised or as part of a group, compared with people who did not exercise.

\section{Key results}

Exercise for osteoarthritis of the hip (Review)

Copyright @ 2014 The Cochrane Collaboration. Published by John Wiley \& Sons, Ltd. 
Pain on a scale of 0 to 100 points (lower scores mean reduced pain):

- People who completed an exercise programme rated their pain to be 8 points lower ( 4 to 11 points lower) at end of treatment ( $8 \%$ absolute improvement) compared with people who did not exercise.

- People who completed an exercise programme rated their pain as 21 points.

- People who did not exercise rated their pain as 29 points.

Physical function on a scale of 0 to 100 points (lower score means better physical function):

- People who completed an exercise programme rated their physical function to be 7 points lower (1 to 12 points lower) at end of treatment (7\% absolute improvement) compared with people who did not exercise.

- People who completed an exercise programme rated their physical function as 22 points.

- People who did not exercise rated their physical function as 29 points.

Quality of life (higher score means better quality of life):

- Overall, people with hip OA participating in the studies had a similar quality of life compared with the general population (normative scores of average 50 points), and quality of life was not further improved by participation in an exercise programme: 0 points higher.

- People who completed an exercise programme rated their quality of life as 50 points on a population norm-based scale.

- People who did not exercise rated their quality of life as 50 points on a population norm-based scale.

Withdrawals

- three more people out of 100 dropped out of the exercise programme ( $1 \%$ absolute increase).

- Six out of 100 people in exercise programmes dropped out.

- Three out of 100 people who did not exercise dropped out.

\section{Quality of the evidence}

This review showed that there is high-quality evidence that in people with hip OA, exercise reduced pain slightly and improved physical function slightly. Further research is unlikely to change the estimate of these results.

Low-quality evidence indicated that exercise may not improve quality of life. Further research is likely to change the estimate of these results.

Moderate-quality evidence showed that exercise probably does not increase study drop-outs. Further research may change the estimate.

We do not have precise information about side effects such as injuries or falls during exercise, but we would expect these to be rare, and no injuries were reported in the studies. 


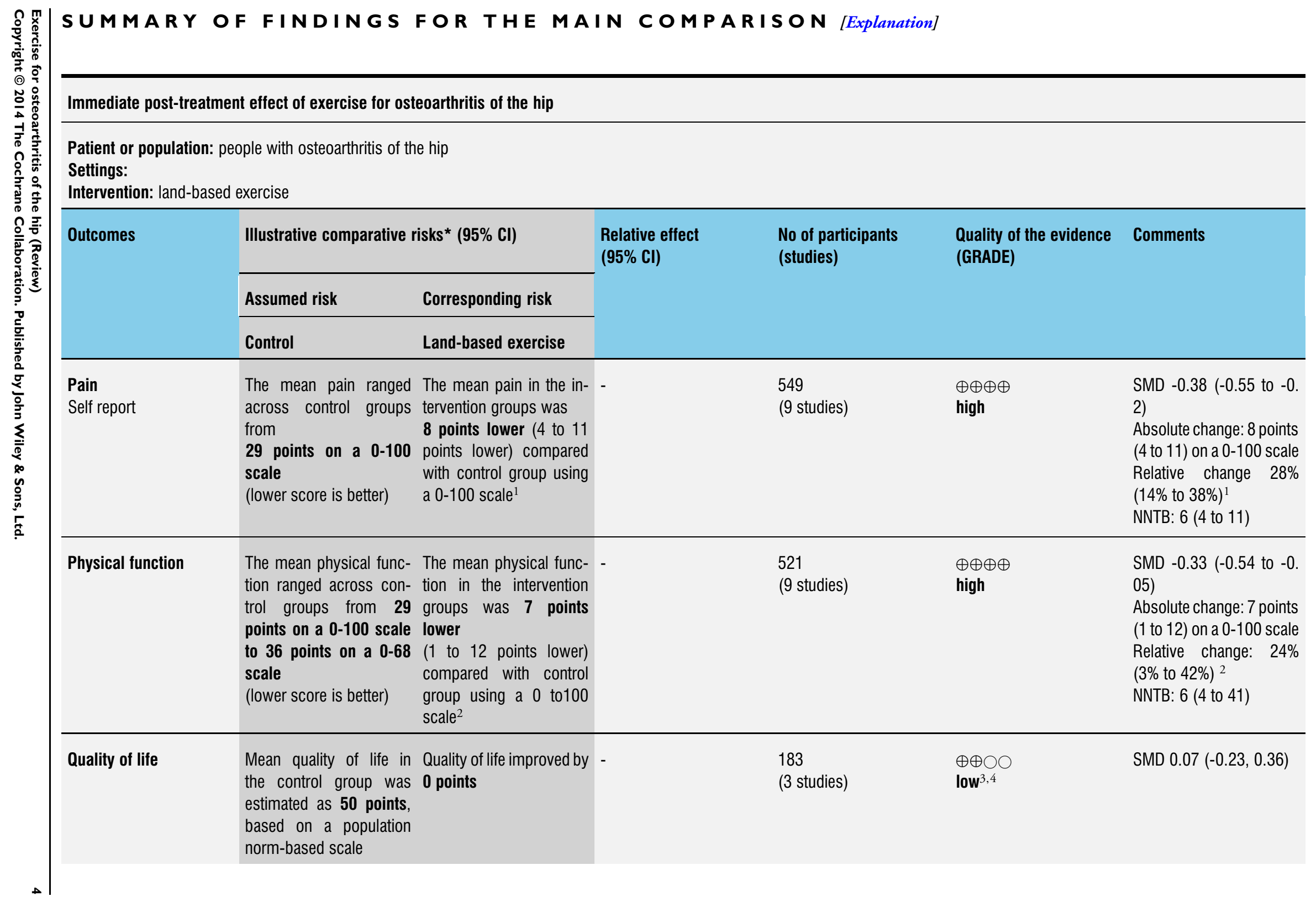




\begin{tabular}{|c|c|c|c|c|c|c|}
\hline Withdrawals or dropouts & 34 per 1000 & $\begin{array}{l}\mathbf{5 9} \text { per } \mathbf{1 0 0 0} \\
(30 \text { to } 114)\end{array}$ & $\begin{array}{l}\text { OR } 1.77 \\
(0.86 \text { to } 3.65)\end{array}$ & $\begin{array}{l}715 \\
\text { (7 studies) }\end{array}$ & $\begin{array}{l}\oplus \oplus \oplus \bigcirc \\
\text { moderate }\end{array}$ & $\begin{array}{l}\text { Absolute risk difference: } \\
1 \% \text { more events ( } 1 \% \\
\text { fewer to } 4 \% \text { more) } \\
\text { Relative difference: } 68 \% \\
\text { increase ( } 13 \% \text { decrease } \\
\text { to } 224 \% \text { increase) }\end{array}$ \\
\hline $\begin{array}{l}\text { Adverse events } \\
\text { not reported }\end{array}$ & See comment & See comment & Not estimable & - & See comment & $\begin{array}{l}\text { No adverse events such } \\
\text { as injuries were reported }\end{array}$ \\
\hline
\end{tabular}

*The basis for the assumed risk (e.g. the median control group risk across studies) is provided in footnotes. The corresponding risk (and its $95 \%$ confidence interval) is based on the assumed risk in the comparison group and the relative effect of the intervention (and its $95 \% \mathrm{Cl}$ ).

Cl: confidence interval; NNTB: number needed to treat for an additional beneficial outcome

GRADE Working Group grades of evidence

High quality: Further research is very unlikely to change our confidence in the estimate of effect.

Moderate quality: Further research is likely to have an important impact on our confidence in the estimate of effect and may change the estimate.

Low quality: Further research is very likely to have an important impact on our confidence in the estimate of effect and is likely to change the estimate.

Very low quality: We are very uncertain about the estimate.

1. Control group baseline mean (standard deviation) was 29.1 (20.2) points on 0- to 100-point scale (Juhakoski 2011).

2. Control group baseline mean (standard deviation) was 28.9 (22.4) points on 0- to 100-point scale (Juhakoski 2011).

3. Potential imprecision, as outcome only reported in three studies.

4. Indirectness: quality of life does not appear to be influenced by mild-to-moderate symptomatic hip $0 \mathrm{~A}$ as the quality of life assessment reported in the two studies using the SF-MCS was in line with published population-based normative values.

5. Imprecison as the number of events were small, and the outcome was poorly reported; many studies reported the number of participants attending outcomes assessments, but did not provide quantitative data regarding the number of participants withdrawing from study treatment. 


\section{B A C K G R O U N D}

\section{Description of the condition}

The prevalence of symptomatic radiographic hip osteoarthritis $(\mathrm{OA})$ increases with age and is estimated to be around 5\% to 15\% for among white people aged 55 years and over (Lawrence 1998; Odding 1998; Moskowitz 2007; Busija 2010). Symptomatic hip $\mathrm{OA}$ is associated with joint pain, physical disability and poor health status (Croft 2002; Dawson 2004), and is the most common reason for total hip replacement surgery. While progression between onset of hip pain to severe symptoms and end-stage disease is variable, disease progression generally appears to be much more rapid than that observed in knee OA (Arden 2006).

\section{How the intervention might work}

Risk factors for incident hip OA include a wide range of local and systemic factors (Arden 2006; Lane 2007; Moskowitz 2007). While age, genetic disposition and many musculoskeletal comorbidity causing hip OA (Paget's disease, developmental deformities of the hip joint, rheumatoid arthritis, etc.) are arguably not modifiable risk factors, improving the mechanical environment of the hip joint and reducing joint loading in this weight-bearing joint have some face validity as useful therapeutic interventions (Zhang 2008). In support, it has been shown that hip OA is associated with markedly reduced lower limb muscle strength (Arokoski 2002; Suetta 2007), and occupations involving a heavy physical load (Fransen 2011).

\section{Why it is important to do this review}

There is no cure for hip OA or treatments proven to slow disease progression. The main treatment goal for people with hip $\mathrm{OA}$, therefore, is to reduce joint pain and physical disability. Current international guidelines for the treatment of hip OA recommend strengthening exercises based on the evidence provided by one meta-analysis (Hernandez-Molina 2008) of benefit in terms of pain reduction (Zhang 2010). However, the $95 \%$ confidence intervals $(\mathrm{CI})$ around the reported small treatment effect (0.38) were wide $(0.08$ to 0.68$)$ and there is currently no evidence of treatment benefit in terms of physical function.

\section{O B J E C T IVES}

To determine whether land-based therapeutic exercise is beneficial for people with hip OA in terms of reduced joint pain, improved physical function and improved quality of life.

\section{METHODS}

\section{Criteria for considering studies for this review}

\section{Types of studies}

Randomised controlled trials (RCTs) or controlled clinical (quasirandomised) trials comparing some form of land-based therapeutic exercise with a non-exercise group.

\section{Types of participants}

Adults, men or women, with either an established diagnosis of hip OA according to accepted criteria or self reporting hip OA on the basis of chronic anterior joint pain (without radiographic confirmation).

\section{Types of interventions}

Any land-based therapeutic exercise regimens aiming to relieve the symptoms of hip OA, regardless of content, duration, frequency or intensity. This included any exercise designed improve muscle strength, range of joint movement or aerobic capacity (or combinations of the three). Programmes could be designed and supervised by physiotherapists or other professionals, or provided as a home programme with minimal monitoring. We included pre-surgery (total hip replacement) programmes. The comparator (control) group could be active (any non-exercise intervention) or placebo (no treatment or waiting list) group. We excluded studies that compared one type of exercise programme versus another exercise programme, provided an exercise programme to all treatment allocations (and evaluated the added benefit of an electrophysical agent or hydrotherapy), compared exercise with manual therapy and compared programmes of varying intensities.

\section{Types of outcome measures}

In accordance with international consensus regarding the core set of outcome measures for phase III clinical trials in OA (Bellamy 1997), the RCT needed to include assessment of at least one of:

- hip pain;

- self reported physical function;

- quality of life.

We assessed these outcomes at two time points: immediately at the end of treatment (post-treatment) and long-term follow-up (sustainability).

In addition, we noted the number of participants withdrawing from the study prior to the post-treatment assessment and the number of participants experiencing adverse events, if provided. 


\section{Search methods for identification of studies}

We searched five databases were searched from inception to February 2013, with no restriction on language: MEDLINE (Appendix 1), EMBASE (Ovid) (Appendix 2), PEDro (Physiotherapy Evidence Database) (Appendix 3), CINAHL (EBSCOhost) (Appendix 4) and The Cochrane Library (Wiley Interscience) (Appendix 5).

We also included a search of ClinicalTrials.gov (www.ClinicalTrials.gov) and the WHO trials portal (www.who.int/ictrp/en/).

\section{Data collection and analysis}

\section{Selection of studies}

Three review authors (MF, SM, GH) independently screened retrieved clinical studies for inclusion. If we did not reach an agreement at any stage, a fourth review author (SR) adjudicated.

\section{Data extraction and management}

Three review authors (MF, SM, GH) extracted data from all included studies and conducted the risk of bias assessment. If we did not reach an agreement at any stage, a fourth review author (SR) adjudicated.

If data on more than one pain scale were provided for a trial, we extracted data from the pain scale that was highest on this list according to a previously described hierarchy of pain-related outcomes (Juni 2006; Reichenbach 2007):

1. Global pain;

2. Pain on walking;

3. Western Ontario and McMaster Universities Osteoarthritis Index (WOMAC) pain subscore;

4. Composite pain scores other than WOMAC;

5. Pain on activities other than walking;

6. Rest pain or pain during the night;

7. WOMAC global algofunctional score;

8. Lequesne Osteoarthritis Index global score;

9. Other algofunctional scale.

If data on more than one physical function scale were reported in a trial, data were extracted according to the hierarchy presented below:

1. Global disability score;

2. Walking disability;

3. WOMAC disability subscore;

4. Composite disability scores other than WOMAC;

5. Disability other than walking;

6. WOMAC global scale;

7. Lequesne Osteoarthritis Index global score;

8. other algofunctional scale.
If data on more than one quality of life scale were reported in a trial, data were extracted according to the hierarchy presented below:

1. 36-item Short Form (SF-36), Mental Component Summary (MCS);

2. 12-item Short Form (SF-12) MCS;

3. EuroQol;

4. Sickness Impact Profile (SIP);

5. Nottingham Health Profile (NHP);

6. other quality of life scales.

\section{Assessment of risk of bias in included studies}

We assessed the risk of bias of included studies in accordance with The Cochrane Collaboration's recommended methods (Risk of bias in included studies).

We assessed the risk of bias according to the following domains.

1. Random sequence generation.

2. Allocation concealment.

3. Blinding of participants and personnel.

4. Blinding of outcome assessment.

5. Incomplete outcome data.

6. Selective outcome reporting.

7. Other bias (baseline imbalances between allocation groups in participant characteristics, occurrence of 'null bias' due to exercise intervention being mostly unmonitored or lengthy period between end of monitored treatment and assessment of outcomes).

We assessed each potential source of bias as high, low or unclear and provided a quote from the study report together with a justification for our judgement in the 'Risk of bias' table. We summarised the risk of bias judgements across different studies for each of the domains listed.

Where information on risk of bias related to unpublished data or correspondence with a trialist, we noted this in the 'Risk of bias' table.

We presented the figures generated by the 'Risk of bias' tool to provide summary assessments of the risk of bias.

If the random sequence generation, allocation concealment and incomplete outcome data domain were adequately met in a study, we judged the overall risk of bias as low for that study.

\section{Measures of treatment effect}

As the studies used a variety of continuous scales to evaluate pain, physical function and quality of life outcomes, a unitless measure of treatment effect size was needed to allow the results of the various RCTs to be combined. We used standardised mean differences (SMD) to calculate treatment effect sizes from the end of treatment scores and related standard deviation (SD) scores, where possible. Therefore, the treatment effect size is a unitless measure providing an indication of the size of the change in terms of its variability. Outcomes pooled using SMD were re-expressed as absolute mean 
difference using a representative control group (high weighting in pooled analyses) baseline SD. We pooled Mantel-Haenszel odds ratios (OR) to calculate the effect of treatment allocation on study withdrawal prior to the first outcomes assessment.

\section{Unit of analysis issues}

The unit of analysis was the participant, and thus there were no unit of analysis issues.

\section{Dealing with missing data}

There were no missing data. We contacted study authors if the data could not be extrapolated in the desired form from the published manuscript.

\section{Assessment of heterogeneity}

In a random-effects model, the overall effects are adjusted to include an estimate of the degree of variation between studies, or heterogeneity, in intervention effect $\left(\mathrm{Tau}^{2}\right)$ (Deeks 2011). The Chi ${ }^{2}$ test assesses whether the differences in results are beyond those that can be attributed to sampling error (chance). The impact of heterogeneity on the meta-analysis results is quantified by the I 2 statistic. This statistic describes the percentage of variability in the effect estimates that is due to heterogeneity rather than chance (Deeks 2011); 30\% to 60\% probably represents moderate heterogeneity while greater than $50 \%$ is usually considered as representing substantial heterogeneity.

\section{Assessment of reporting biases}

For studies published after 1 July 2005, we screened the Clinical Trial Register at the International Clinical Trials Registry Platform of the World Health Organization (apps.who.int/trialssearch) for the a priori trial protocol. We evaluated whether selective reporting of outcomes is present (outcome reporting bias).

To assess for potential small-study effects in meta-analyses (i.e. the intervention effect is more beneficial in smaller studies), we compared effect estimates derived from a random-effects model and a fixed-effect model of meta-analysis. In the presence of smallstudy effects, the random-effects model will give a more beneficial estimate of the intervention than the fixed-effect estimate (Sterne 2011)

\section{Data synthesis}

We used the random-effects model to combine outcomes.

\section{'Summary of findings' table}

We created a 'Summary of findings' table using the following outcomes: pain, self reported physical function and adverse events, and also quality of life and withdrawals for the immediate post treatment time point. We assessed the quality of the evidence using the five GRADE considerations (study limitations, consistency of effect, imprecision, indirectness and publication bias) to assess the quality of a body of evidence for the outcomes using GRADEpro software (Schünemann 2011a; Schünemann 2011b).

Outcomes pooled using SMD were re-expressed as absolute mean difference using a representative control group baseline SD from a trial using a familiar instrument and dividing by the points of the measurement scale and expressed as a percentage.

In the comments column of the 'Summary of findings' table, we have presented the absolute per cent difference, the relative per cent change from baseline and the number needed to treat for an additional beneficial outcome (NNTB), or an additional harmful outcome (NNTH) (the number needed to treat (NNT) is only provided for outcomes with statistically significant differences between the intervention and control groups).

For dichotomous outcomes, the absolute risk difference was calculated using the risk difference statistic in Review Manager 5 (RevMan 2012) and the result expressed as a percentage; the relative percentage change was calculated as the risk ratio -1 and was expressed as a percentage; and the NNT from the control group event rate and the risk ratio were determined using the Visual $\mathrm{Rx}$ NNT calculator (Cates 2008).

For continuous outcomes, the absolute risk difference was calculated as the mean difference between intervention and control groups in the original measurement units (divided by the scale), expressed as a percentage; the relative difference was calculated as the absolute change (or mean difference) divided by the baseline mean of the control group from a representative trial. We used the Wells calculator to obtain the NNTB for continuous measures (available at the Cochrane Musculoskeletal Group (CMSG) Editorial office; musculoskeletal.cochrane.org/). The minimal clinically important difference (MCID) for each outcome was determined for input into the calculator. We assumed an MCID of 15 points on a 0 - to 100 -point pain scale; and 10 points on a 0 - to 100 -point function scale.

\section{Subgroup analysis and investigation of heterogeneity}

We evaluated the influence of using end of treatment or change scores for the investigation of heterogeneity.

\section{Sensitivity analysis}

To evaluate potential exercise programme targeting, we conducted a sensitivity analysis to assess the impact of recruiting solely participants with hip OA compared with recruiting participants with hip or knee OA. 


\section{Description of studies}

Of the 44 retrieved RCTs identified from the literature search (Figure 1), 10 met the inclusion criteria (van Baar 1998; HopmanRock 2000; Foley 2003; Tak 2005; Fransen 2007; Fernandes 2010; Carlson 2011; Juhakoski 2011; Abbott 2013; French 2013) and are detailed in the Characteristics of included studies table. Of the 10 studies, only five recruited solely participants with symptomatic hip OA (Tak 2005; Fernandes 2010; Carlson 2011; Juhakoski 2011; French 2013). The other five studies recruited participants with either hip OA or knee OA, or both. These five RCTs provided data specific for the participants indicating the hip joint as either the only symptomatic joint or the most symptomatic (signal) joint for pain reporting. Two studies included three allocations, each having a land-based exercise allocation (gym-based classes (Foley 2003) or Tai Chi classes (Fransen 2007), a hydrotherapy allocation and a waiting list control group. For the current meta-analysis, the land-based exercise allocation was compared with the waiting list control group. Two further studies had an exercise allocation (individual treatments) in addition to an allocation to exercise plus manual therapy (Abbott 2013; French 2013). For these two studies, the exercise (alone) allocation was compared with the waiting list or usual care control group. 
Figure I. Study flow diagram.

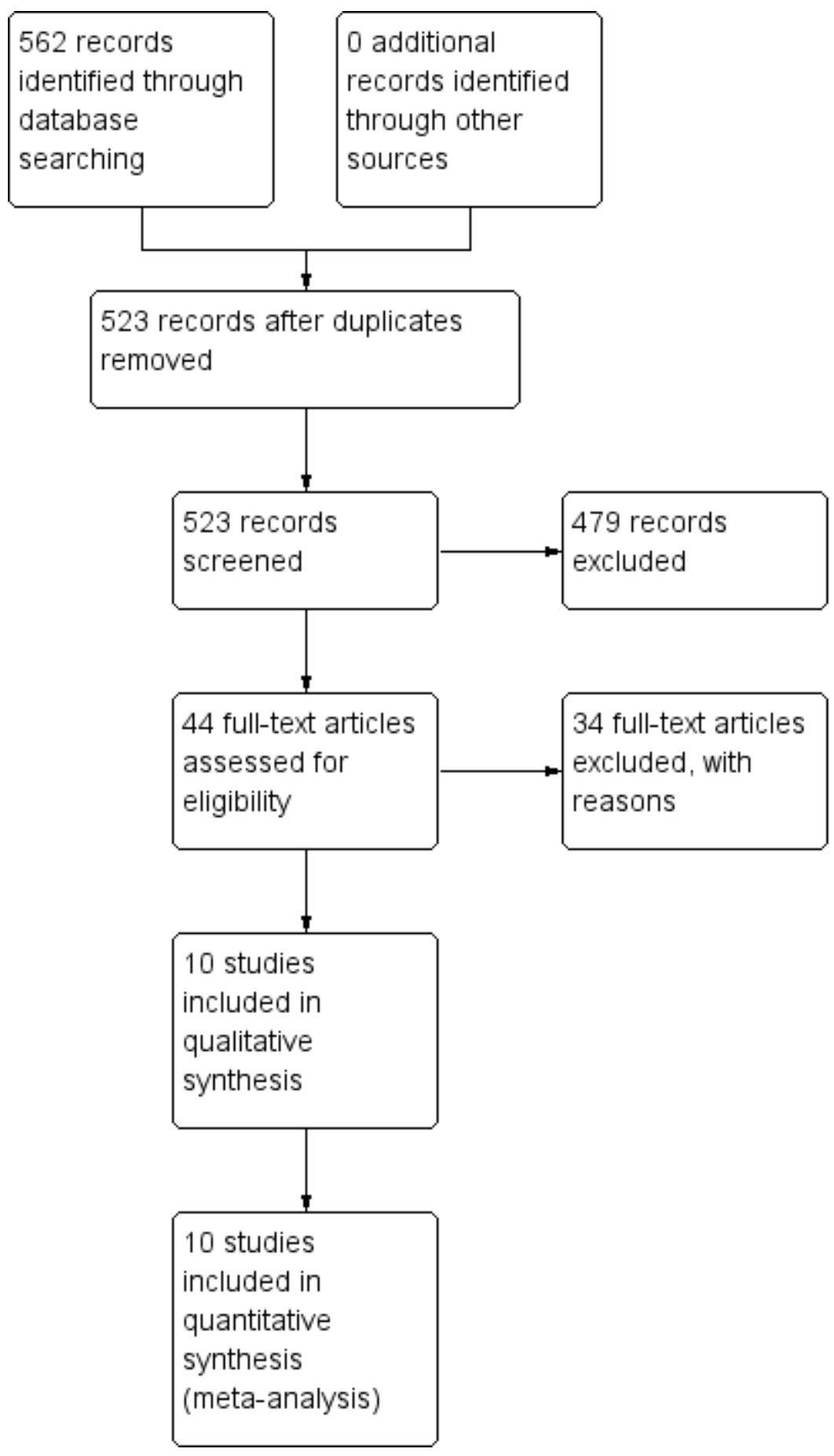


We excluded 34 studies for reasons provided in the Characteristics of excluded studies table (Figure 1).

Only two RCTs had more than 50 participants in each allocation group (Fernandes 2010; Juhakoski 2011).

There was large variability in treatment dosage. Four studies provided fewer than 10 supervised sessions (Hopman-Rock 2000; Tak 2005; Abbott 2013; French 2013). Five studies provided access to at least 16 sessions. Six of the 10 RCTs evaluated class-based programmes, while the other four studies provided treatments as individual sessions with a physiotherapist (van Baar 1998; Fernandes 2010; Abbott 2013; French 2013). While one RCT evaluated a specific 'Tai Chi for Arthritis' programme (Fransen 2007), the other studies evaluated more traditional muscle strengthening, functional training and aerobic fitness programmes.

Sample recruitment varied widely. Four RCTs recruited community volunteers (Hopman-Rock 2000; Tak 2005; Fransen 2007; Juhakoski 2011), one RCT recruited participants through general practice (van Baar 1998), and four recruited mostly through specialist clinics (Foley 2003; Carlson 2011; Abbott 2013; French 2013). The variability in recruitment strategies resulted in marked differences in study participant samples. Approximately $50 \%$ of participants in one RCT reported a symptom duration of less than one year (van Baar 1998), while another RCT included a large proportion $(40 \%)$ of participants who were already on the orthopaedic surgery waiting list (Foley 2003).

Seven included RCTs used the WOMAC to evaluate pain or physical function, or both (Foley 2003; Fransen 2007; Fernandes 2010; Carlson 2011; Juhakoski 2011; Abbott 2013; French 2013). One study used a numerical rating scale to evaluate pain (with activ- ity), while using the WOMAC subscale to evaluate physical function (French 2013). The other three studies, all conducted in The Netherlands, used a $10-\mathrm{cm}$ visual analogue scale (VAS) to evaluate hip pain and either the Influence of Rheumatic Diseases on General Health and Lifestyle (IRGL) questionnaire (van Baar 1998; Hopman-Rock 2000) or the Groningen Activity Restriction Scale (GARS) (Tak 2005) to evaluate physical function. The GARS measures level of disability performing 18 daily activities with a score ranging from 18 (no problems) to 72 (only with help from others).

For pain and physical function, nine RCTs provided immediate post-treatment outcomes assessments, while five RCTs evaluated treatment sustainability three to six months after completion of the supervised exercise programme. Only five RCTs provided quality of life assessments (Hopman-Rock 2000; Foley 2003; Tak 2005; Fransen 2007; French 2013). Data specific for participants with hip OA could only be provided by three studies (Tak 2005; Fransen 2007; French 2013). Two of these studies provided the population-based SF-12 MCS scores as an indicator of quality of life (Fransen 2007; French 2013), while one study used a generic 0 to 10 VAS scale (Tak 2005). Quality of life data, specific for hip OA participants, were not available from two older studies reported in the original review (Hopman-Rock 2000; Foley 2003).

\section{Risk of bias in included studies}

One RCT was only reported as a conference abstract with insufficient information to evaluate risk of bias criteria (Carlson 2011) (Figure 2). 
Figure 2. Risk of bias summary: review authors' judgements about each risk of bias item for each included study.

\begin{tabular}{|c|c|c|c|c|c|c|c|}
\hline & 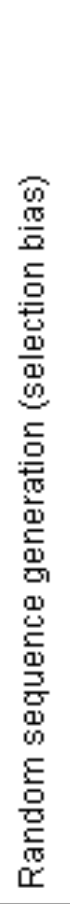 & 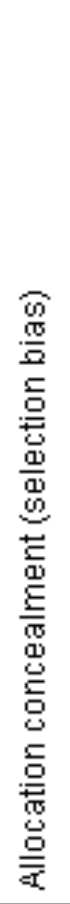 & 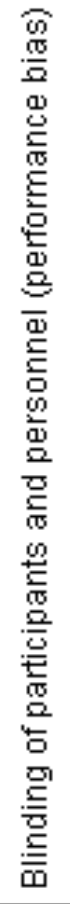 & 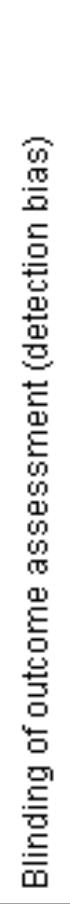 & 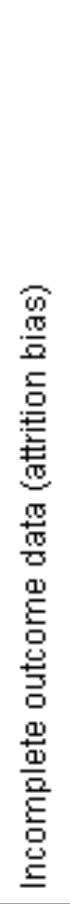 & 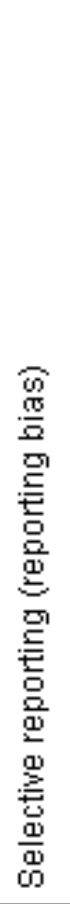 & 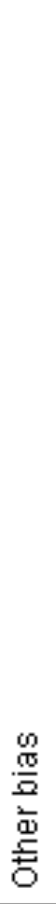 \\
\hline Abbott 2013 & + & + & C & $?$ & + & + & $?$ \\
\hline Carlson 2011 & $?$ & $?$ & 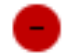 & $?$ & $?$ & $?$ & $?$ \\
\hline Fernandes 2010 & + & + & & $?$ & $\bullet$ & + & 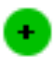 \\
\hline Foley 2003 & + & + & & $?$ & + & $?$ & $?$ \\
\hline Fransen 2007 & + & + & & $?$ & 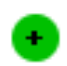 & + & + \\
\hline French 2013 & + & + & & $?$ & + & + & + \\
\hline Hopman-Rock 2000 & $?$ & $?$ & & $?$ & $?$ & $?$ & + \\
\hline Juhakoski 2011 & + & + & & $?$ & + & $?$ & + \\
\hline Tak 2005 & + & $?$ & & $?$ & & $?$ & + \\
\hline van Baar 1998 & + & + & & $?$ & $\oplus$ & $?$ & + \\
\hline
\end{tabular}




\section{Allocation}

We considered seven of the 10 included RCTs as 'low risk of bias' for allocation concealment (van Baar 1998; Foley 2003; Fransen 2007; Fernandes 2010; Juhakoski 2011; Abbott 2013; French 2013), while three had 'uncertain risk' (Hopman-Rock 2000; Tak 2005; Carlson 2011), as no specific information was provided (Figure 2).

\section{Blinding}

None of the included RCTs was able to blind participants or personnel (therapists providing the interventions) to treatment allocation (Figure 2).

While all of the included RCTs reported blinding of outcomes assessor, the outcomes (pain, physical function, quality of life) were participant reported and results may, therefore, be vulnerable to detection bias.

\section{Incomplete outcome data}

Eight of the 10 included RCTs had only minimal loss to followup or used intention-to-treat analysis.

\section{Selective reporting}

Only four of the 10 included RCTs indicated evidence of study registration.

\section{Other potential sources of bias}

There were three studies with unclear risk of other biases: lengthy period (eight months) between end of supervised treatment programme and outcomes assessment (Abbott 2013); abstract only so minimal information on study methodology (Carlson 2011); $40 \%$ of participants on the orthopaedic surgery waiting list (Foley 2003).

\section{Effects of interventions}

See: Summary of findings for the main comparison Immediate post-treatment effect of exercise for osteoarthritis of the hip; Summary of findings 2 Sustainability (three to six months) for osteoarthritis of the hip

We contacted four study authors to provide data specific for OA hip for pain and physical function outcomes (van Baar 1998; Hopman-Rock 2000; Foley 2003; Abbott 2013). All four responded with the requested data. We were unable to contact the authors of one included pilot study that had been published as an abstract (Carlson 2011).

\section{Immediate post treatment}

\section{Pain}

Nine of the 10 included RCTs provided immediate post-treatment effects on 549 participants.

Combining the results demonstrated a significant benefit (SMD (random-effects model) $-0.38,95 \%$ CI -0.55 to -0.20 ; Figure 3 ). This effect size would be considered small to moderate (Cohen 1977). Between-study heterogeneity was negligible $\left(\mathrm{I}^{2}=0 \%\right)$. The demonstrated effect size for exercise was equivalent to a pain reduction of 8 points ( $95 \%$ CI 4 to 11 ) on a 0 to 100 scale compared with a control group. 
Figure 3. Forest plot of comparison: I.I Pain.

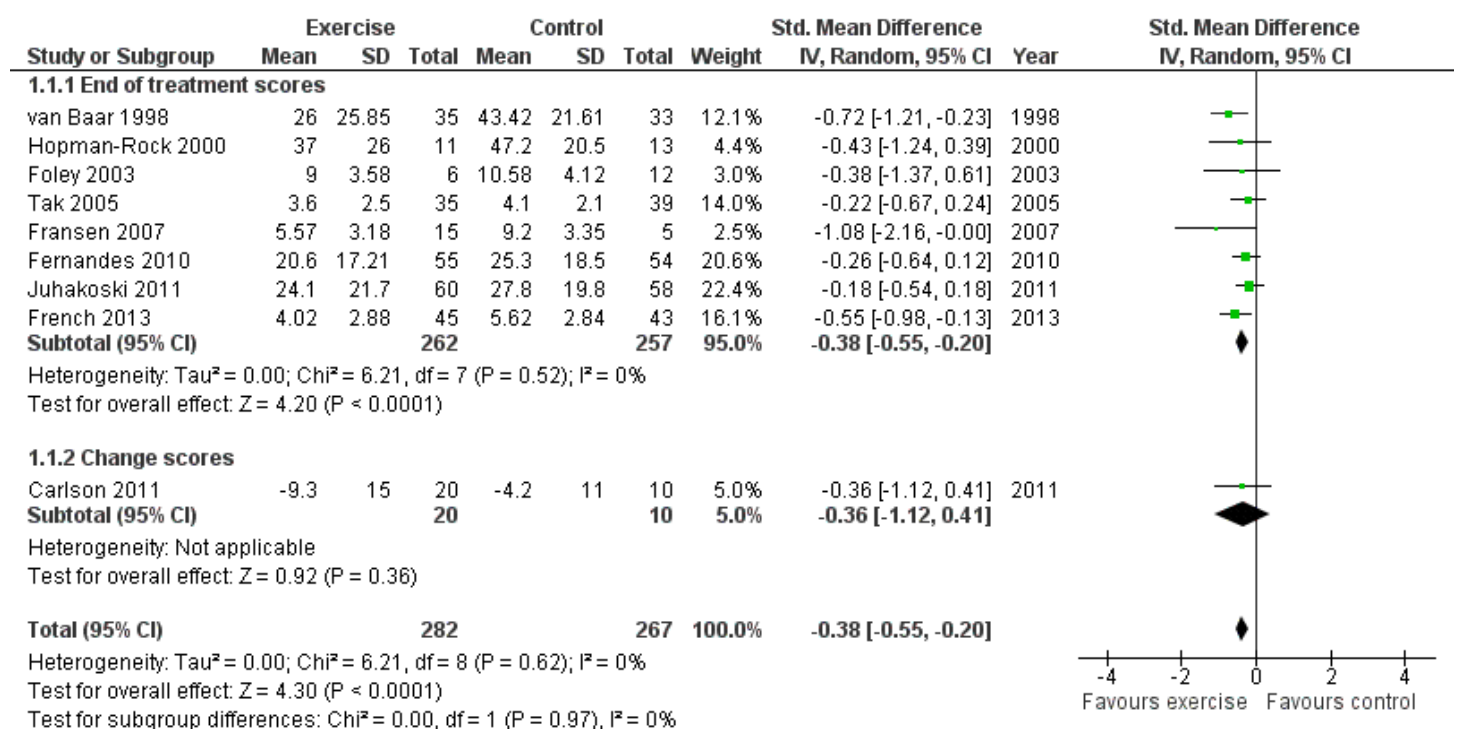

\section{Physical function}

Nine of the 10 included RCTs provided immediate post-treatment effects on 521 participants.

Combining the results demonstrated a significant benefit (SMD $-0.30,95 \%$ CI -0.54 to -0.05 ; Figure 4). Between-study heterogeneity was moderate $\left(\mathrm{I}^{2}=41 \%\right)$. Limiting pooling to the six RCTs providing post-treatment scores, rather than change scores, resulted in a similar benefit (SMD -0.33, 95\% CI -0.53 to 0.13 ) and reduced between-study heterogeneity to $0 \%$. This effect size would be considered small to moderate (Cohen 1977). The demonstrated effect size for exercise was equivalent to an improvement of physical function of 7 points ( $95 \%$ CI 1 to 12 ) on a 0 to 100 scale compared with a control group. 
Figure 4. Forest plot of comparison: I.2 Physical function.

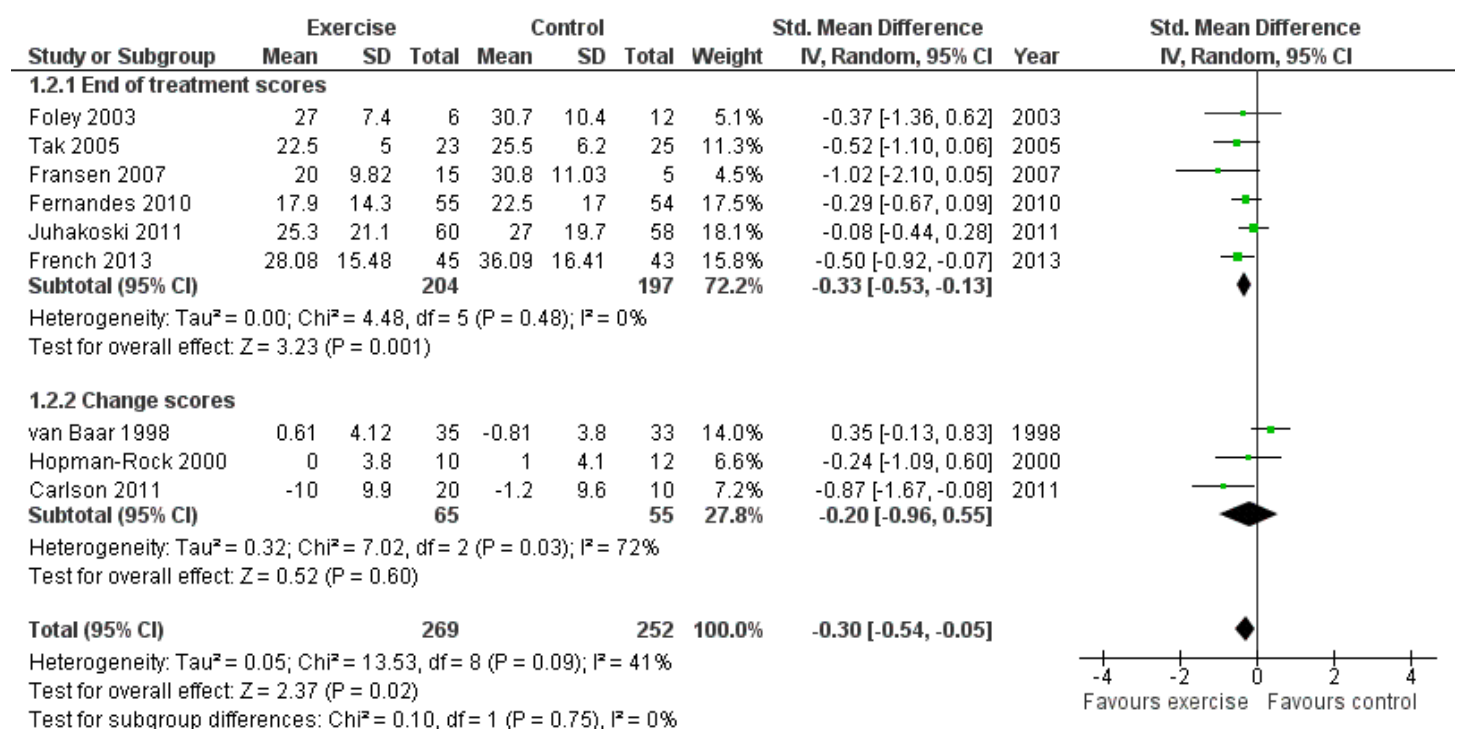

\section{Quality of life}

Only three of the 10 included RCTs could provide immediate posttreatment effects on 183 participants with hip OA. A higher score is a better score. Two studies used population norm-based scores with a mean of 50 (SD 10). No significant difference was detected (SMD $0.10,95 \%$ CI -0.23 to 0.36 ). Between-study heterogeneity was negligible $\left(\mathrm{I}^{2}=0 \%\right)$.

\section{Study withdrawals}

Only seven studies provided data on study withdrawals at the time of the first post-treatment assessment. Of these seven studies, only whole sample estimates (knee and hip OA) were available for two studies (van Baar 1998; Foley 2003). There was no significantly

increased risk of study withdrawal from the exercise allocation $(6.3 \%)$ compared with the control group (3.4\%) (Risk difference 0.01, 95\% CI -0.01 to 0.04); Analysis 1.4).

\section{Treatment sustainability (three to six months)}

\section{Pain}

Five of the 10 included RCTs provided treatment sustainability pain outcomes on 391 participants. Combining the results demonstrated a significant benefit (SMD $-0.38,95 \%$ CI -0.58 to -0.18 ; Figure 5). Between-study heterogeneity was negligible $\left(\mathrm{I}^{2}=0 \%\right)$. This effect size would be considered small to moderate (Cohen 1977). 
Figure 5. Sustainability (three to six months), outcome: 2.I Pain.

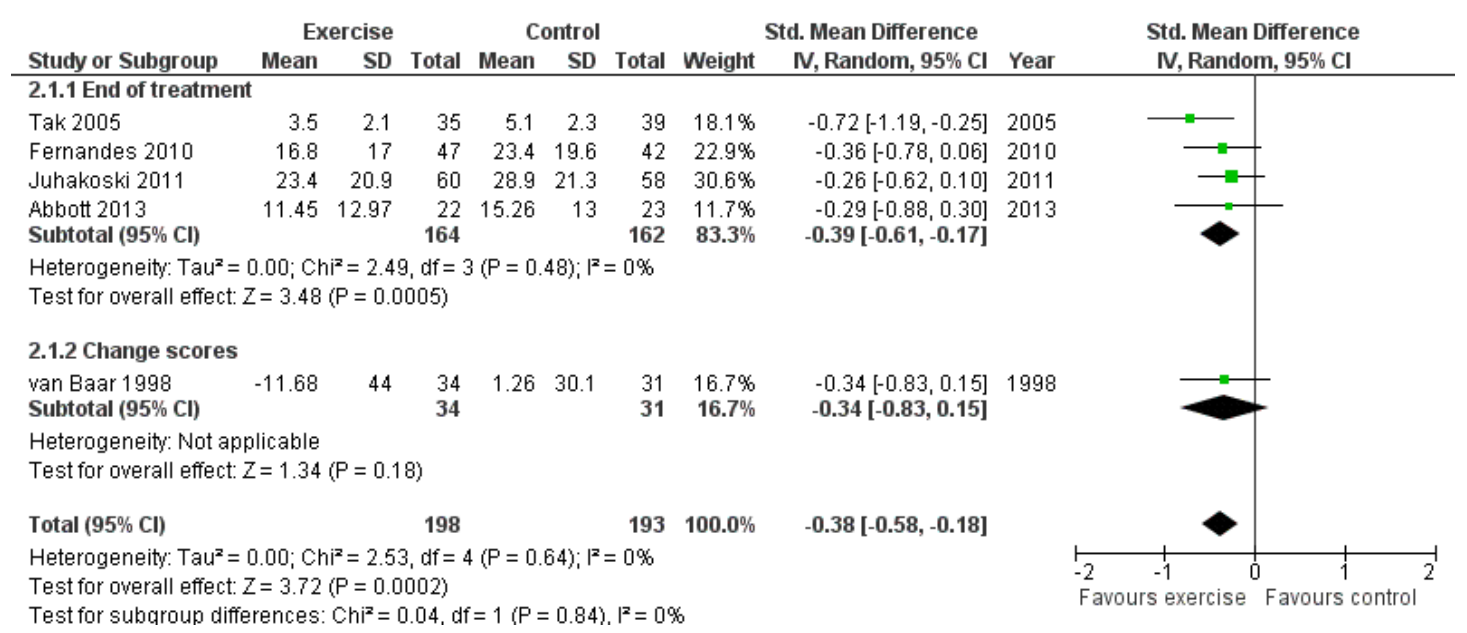

\section{Physical function}

Five of the 10 included RCTs provided treatment sustainability physical function outcomes on 365 participants. Combining the results demonstrated a significant benefit (SMD - $0.37,-0.57$ to -0.16 ; Figure 6). Between-study heterogeneity was negligible $\left(\mathrm{I}^{2}\right.$ $=0 \%)$. This effect size would be considered small to moderate (Cohen 1977).

Figure 6. 2 Sustainability (three to six months), outcome: 2.2 Physical function.

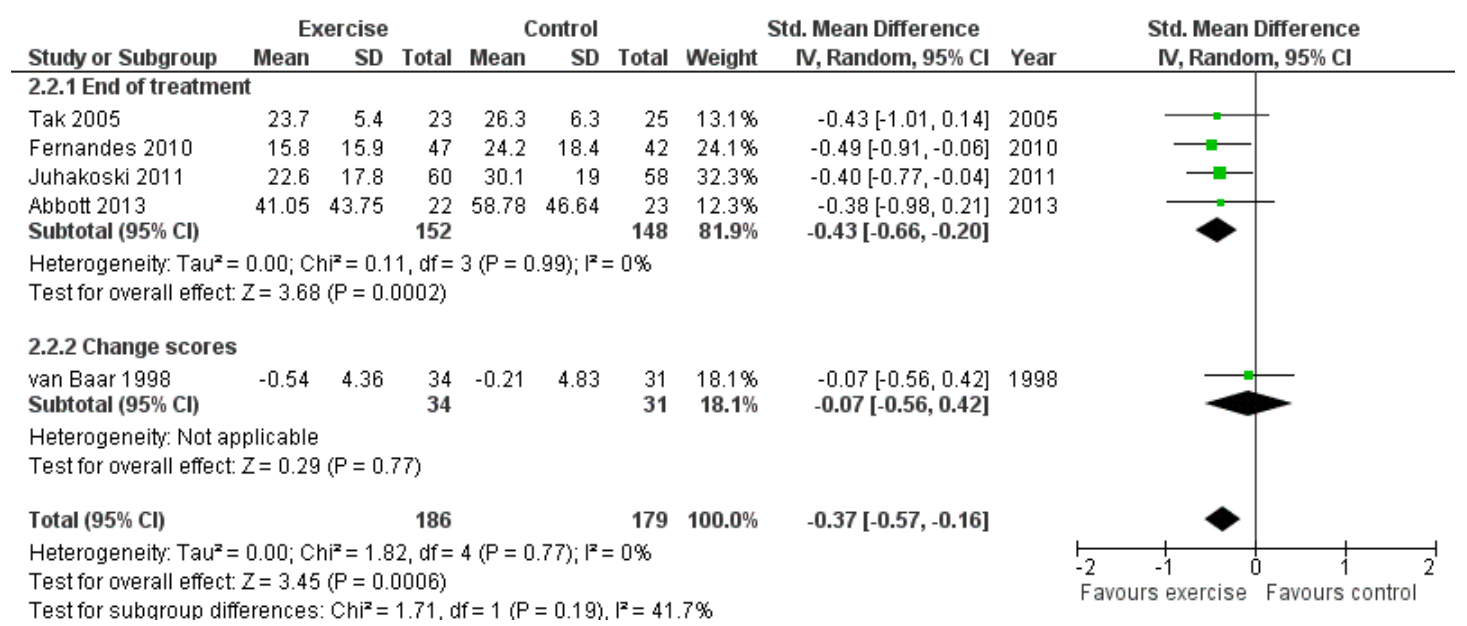

Studies recruiting only participants with hip osteoarthritis compared with studies recruiting

Exercise for osteoarthritis of the hip (Review)

Copyright $\odot 2014$ The Cochrane Collaboration. Published by John Wiley \& Sons, Ltd. 
participants with hip and knee osteoarthritis

\section{Pain}

Combining the results of the five studies (419 participants) recruiting solely people with hip OA demonstrated a significant benefit (SMD -0.30, 95\% CI -0.49 to -0.10). Combining the results of the four studies (130 participants) recruiting people with either hip or knee OA demonstrated a larger mean benefit (SMD -0.66, $95 \%$ CI -1.02 to -0.29$)$. There was no significant difference between the two groups of studies $(\mathrm{P}$ value $=0.09)$.

\section{Physical function}

Combining the results of the five studies (393 participants) recruiting solely people with hip OA demonstrated a significant benefit (SMD $-0.35,95 \%$ CI -0.57 to -0.13). Combining the results of the four studies (128 participants) recruiting people with either hip or knee OA did not detect a significant benefit (SMD -0.20, $95 \% \mathrm{CI}-0.79$ to 0.40 ). There was no significant difference between the two groups of studies ( $\mathrm{P}$ value $=0.64$ ). Between-study heterogeneity was substantial for the studies recruiting participants with either hip or knee OA $\left(\mathrm{I}^{2}=54 \%\right)$.

\section{Adverse events}

Only five RCTs specifically reported adverse events (van Baar 1998; Foley 2003; Tak 2005; Fransen 2007; Abbott 2013).

Abbott 2013 "detected no trial related adverse events", van Baar 1998 stated one patient receiving exercise reported adverse effects; Tak 2005 reported two participants in the exercise group withdrew due to increased back pain; Foley 2003 reported four withdrawals in the exercise group due to increased pain (two people), increased blood pressure (one person) and doctor's advice (one person) compared with one withdrawal due to illness in the control group; and Fransen 2007 reported only withdrawals in the Tai Chi allocation among participants with knee OA. 


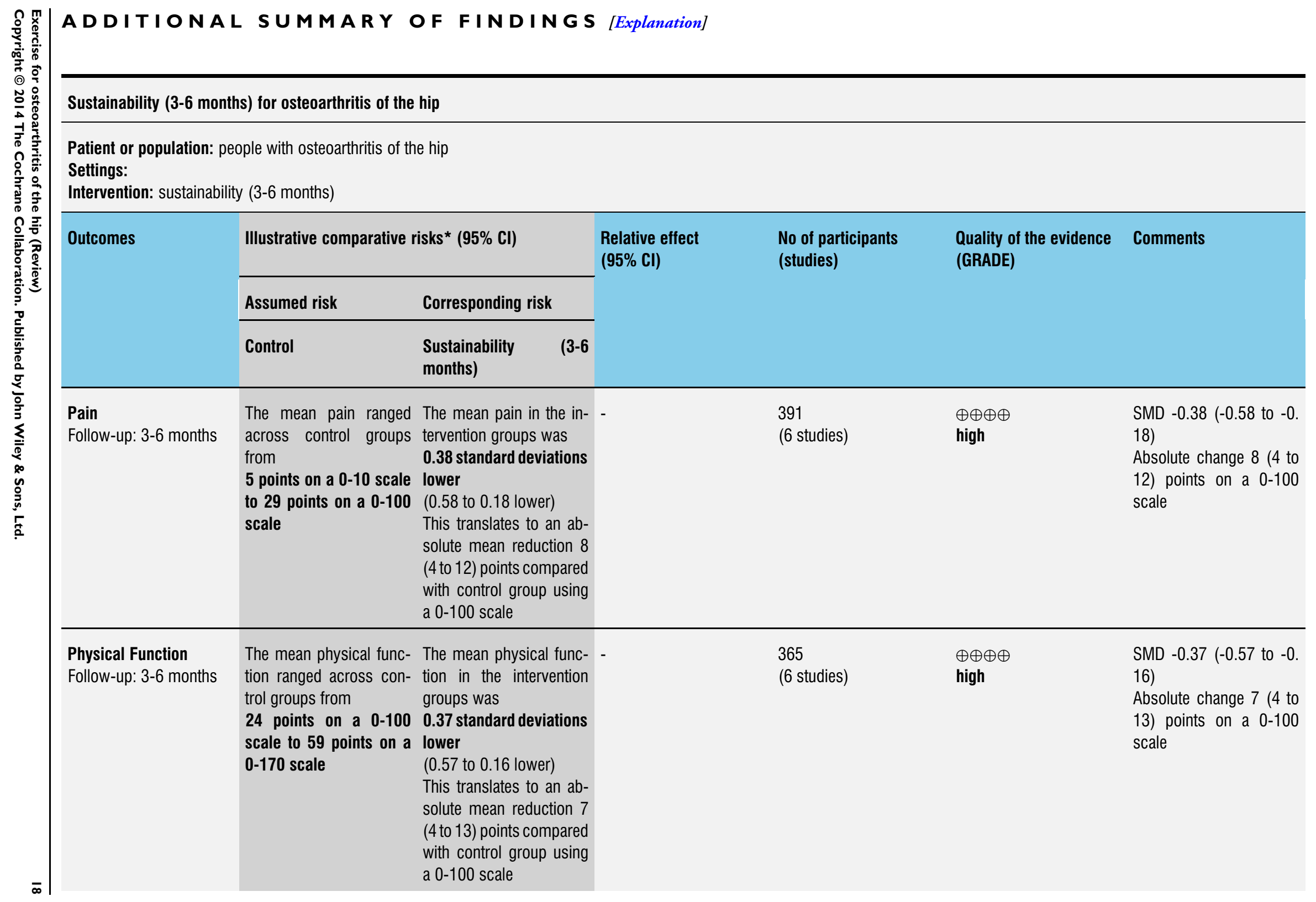




\begin{tabular}{|c|c|c|c|c|c|}
\hline $\begin{array}{l}\text { Adverse events } \\
\text { not reported }\end{array}$ & See comment & See comment & Not estimable & See comment & $\begin{array}{l}\text { No adverse events such } \\
\text { as injuries were reported }\end{array}$ \\
\hline
\end{tabular}

*The basis for the assumed risk (e.g. the median control group risk across studies) is provided in footnotes. The corresponding risk (and its $95 \%$ confidence interval) is based on the assumed risk in the comparison group and the relative effect of the intervention (and its $95 \% \mathrm{Cl}$ ).

Cl: confidence interval; NNTB: number needed to treat for an additional beneficial outcome

GRADE Working Group grades of evidence

High quality: Further research is very unlikely to change our confidence in the estimate of effect.

Moderate quality: Further research is likely to have an important impact on our confidence in the estimate of effect and may change the estimate.

Low quality: Further research is very likely to have an important impact on our confidence in the estimate of effect and is likely to change the estimate.

Very low quality: We are very uncertain about the estimate. 


\section{ISCUSSION}

\section{Summary of main results}

The objective of this systematic review was to evaluate the current scientific evidence for the benefit of land-based exercise for people with symptomatic hip OA in terms of joint pain, self reported physical function and quality of life. The overall results of the meta-analysis suggest that land-based exercise is beneficial in terms of reduced pain and improved physical function at the completion of a supervised exercise programme and these benefits are sustained for at least a further three to six months. There was insufficient evidence available to determine the effect of exercise on quality of life among people with hip OA. The level of pain was generally mild to moderate at baseline and thus although the reduction in pain in favour of exercise was potentially small (a mean absolute change of $8 \%$ ), a mean relative change of $28 \%$ (38\% for the upper limit) could be considered clinically important for a lowrisk intervention such as exercise. Similarly for physical function, a relative change of $42 \%$ could not be ruled out.

\section{Overall completeness and applicability of evidence}

The meta-analysis could include 10 small RCTs. There were marked differences between these RCTs in the content and duration of the exercise programmes provided and in the participant samples recruited. Only one of the larger RCTs demonstrated significant benefits in both pain and physical function at the end of the treatment programme (French 2013). This study provided only eight weekly sessions of individually supervised exercise sessions but also prescribed a daily home programme of 30 minutes of walking, cycling or swimming. One other study demonstrated significant benefit in terms of pain only (van Baar 1998). The participants in this study were referrals from general practice with mostly very early symptomatic disease (less than one year). The two largest RCTs were the only studies to demonstrate significant sustainable benefit at three to six months for physical function (Fernandes 2010; Juhakoski 2011). The first provided 24 individual sessions with a physiotherapist over 12 weeks (Fernandes 2010). The exercise programme had a mixed content of muscle strengthening and functional exercise. The second provided 16 sessions of high-intensity muscle strengthening (Juhakoski 2011). It is notable that these three RCTs demonstrating significant benefits were among the five RCTs that restricted recruitment to people with hip OA. Of the other two RCTs restricting recruitment to only participants with hip OA, one had a much smaller sample size (Tak 2005), and the other did not evaluate long-term outcomes (Carlson 2011). It is likely that their exercise programmes were, therefore, more specific to this condition compared to RCTs that recruited both people with knee, hip or both knee and hip OA. This concern would be particular for hip OA as the proportion of participants with hip OA in these combined programmes is always much smaller than the proportion with knee OA. The proportion of RCTs restricting recruitment to people with hip OA was much higher for this update (5/10 studies), compared with the previous review (1/5 studies), and may explain the shift to finding significant improvement for physical function in the current update. It would be worthwhile if future studies explore the effect of more intensive lower limb muscle strengthening programmes further and provide more information regarding exercise adherence or the effect of strategies to improve exercise adherence in this population. We have still only been able to include five studies specifically targeting people with hip OA. Exercise covers a very broad area, so the potential for development of more beneficial and sustainable exercise protocols is evident. A larger number of studies would allow for meaningful subgroup analyses on basis of exercise content and dosage.

\section{Quality of the evidence}

Most of the RCTs included in this systematic review were considered by our criteria to have a 'low risk of bias'. While all the RCTs reported having blinded outcome assessment, participants were aware of their allocation status. Given that the main outcomes of this review were participant self reported pain and physical function, there is a possibility that the treatment effect sizes may be inflated. Given the difficulty blinding participants to exercise treatment allocation (versus no exercise) and the high quality of the evidence for pain and physical function benefit, we expect that new studies would not change our confidence in the effect estimates.

The quality of the body of evidence was high for pain and function. Although there may be a potential study limitation for the evidence for pain and function (a potential for bias that may overestimate the effect sizes), we did not consider that it was substantial enough to downgrade the evidence. The evidence underpinning quality of life was low overall due to the limited number (three) of small studies evaluating this outcome. Further, quality of life does not appear to be influenced by mild-to-moderate symptomatic hip $\mathrm{OA}$ as the quality of life assessment reported in the two studies using the SF-MCS was in line with published population-based normative values. The evidence for withdrawals was moderate due to unspecific reporting. Many studies simply reported the number of participants attending outcomes assessments, and did not provide quantitative data regarding the number of participants withdrawing from study treatment.

\section{Potential biases in the review process}

We expect minimal biases in extracting and reporting of data (four review authors selected studies for inclusion, two review authors independently extracted data). We conducted an extensive liter- 
ature search. However, the possibility of publication bias could not be ruled out, as we did not attempt to retrieve unpublished studies.

\section{Agreements and disagreements with other studies or reviews}

The mean effect size for immediate post-treatment hip pain reported in this meta-analysis were similar to those reported in a previous meta-analysis (SMD -0.38) (Hernandez-Molina 2008). The previous meta-analysis included five RCTs from 1998 to 2007 included in this review, but also included three further RCTs evaluating hydrotherapy, as well as the hydrotherapy results of two included RCTs (Foley 2003; Fransen 2007). While the mean effect size was identical, the CIs around the estimate were much wider (95\% CI 0.08 to 0.68 ) than those demonstrated in the current review (95\% CI 0.20 to 0.55 ). The original Cochrane review, "Exercise for osteoarthritis of the hip" (Fransen 2009), could only pool the findings of five RCTs with 204 participants. This previous review did not demonstrate a significant benefit in terms of pain and physical function. Marked heterogeneity was evident and only one of the five RCTs restricted recruitment to people with hip OA (Tak 2005). In the current review, about $75 \%$ of study participants were enrolled in RCTs restricting recruitment to people with hip OA.

\section{Implications for practice}

There is currently high-level evidence that land-based exercise will reduce hip pain (van Baar 1998; French 2013), and improve physical function (Fernandes 2010; Juhakoski 2011; French 2013), among people with symptomatic hip osteoarthritis.

\section{Implications for research}

Identify possible predictors of treatment responsiveness and exercise adherence in this population.

Develop multi-armed randomised controlled trials to help provide evidence of optimal exercise content and dosage. Initiate research to assess the long-term effectiveness of exercise for people with hip osteoarthritis in terms of disease progression and time to joint replacement surgery.

\section{ACKNOWLEDGEMENTS}

Ms Louise Falzon, Mt Sinai Medical Centre, New York, for designing the literature search strategy.

Dr Renea Johnston, Managing Editor, Australian Editorial Base, Cochrane Musculoskeletal Group, for overall guidance and expert advice.

Tamara Reader, Cochrane Musculoskeletal Group, for designing the updated literature search strategy.

Jordi Pardo Pardo, Cochrane Musculoskeletal Group, for overall guidance and support.

\section{A U THORS, CONCLUSIONS}

\section{R E F E R E N C E S}

\section{References to studies included in this review}

Abbott 2013 \{published and unpublished data\} Abbott JH, Robertson MC, Chapple C, Pinto D, Wright AA, Leon de la Barra $S$, et al.Manual therapy, exercise therapy, or both, in addition to usual care, for osteoarthritis of the hip or knee: a randomized controlled trial. A: clinical effectiveness. Osteoarthritis and Cartilage 2013;21:525-34.

Carlson 2011 \{published data only\}

Carlson NL, Christopherson Z, Arnall E, Mohn S, Holton $\mathrm{K}$, Marshall L, et al.A pilot study of the effects of strength and aerobic conditioning in patients with hip osteoarthritis. Osteoarthritis and Cartilage 2011;19:S212.

Fernandes 2010 \{published data only\}

Fernandes L, Storheim K, Sandvik L, Nordsletter L, Risberg MA. Efficacy of patient education and supervised exercise vs patient education alone in patients with hip osteoarthritis: a single blind randomized clinical trial. Osteoarthritis and Cartilage 2010;18:1237-43.
Foley 2003 \{published data only\}

Foley A, Halbert J, Hewitt T, Crotty M. Does hydrotherapy improve strength and physical function in patients with osteoarthritis - a randomised controlled trial comparing a gym based and a hydrotherapy based strengthening program. Annals of the Rheumatic Diseases 2003;62:1162-7.

Fransen 2007 \{published data only\}

Fransen M, Nairn L, Winstanley J, Lam P, Edmonds J. The Physical Activity for Osteoarthritis Management (PAFORM) study. A randomised controlled clinical trial evaluating hydrotherapy and Tai Chi classes. Arthritis Care and Research 2007;57:407-14.

French 2013 \{published data only\}

* French HP, Cusak T, Brennan A, Caffrey A, Conroy R, Cuddy V, et al.Exercise and manual physiotherapy arthritis research trial (EMPART) for osteoarthritis of the hip: a multicentre randomised controlled trial. Archives of Physical Medicine and Rehabilitation 2013;94:302-14. 
Hopman-Rock 2000 \{published data only\}

Hopman-Rock M, Westhoff $M$. The effects of a health educational and exercise program for older adults with osteoarthritis of the hip or knee. Journal of Rheumatology 2000;27:1947-54.

Juhakoski 2011 \{published and unpublished data\} Juhakoski R, Tenhonen S, Malmivaara A, Kiviniemi V, Anttonen T, Arokoski J. A pragmatic randomized controlled study of the effectiveness and cost consequences of exercise therapy in hip osteoarthritis. Clinical Rehabilitation 2011; 25:370-83.

Tak 2005 \{published data only\}

Tak E, Staats P, Van Hespen A, Hopman-Rock A. The effects of an exercise program for older adults with osteoarthritis of the hip. Journal of Rheumatology 2005;6:1106-13.

van Baar 1998 \{published data only\} van Baar ME, Dekker J, Oostendorp RAB, Bijl D, Voorn $\mathrm{TB}$, Lemmens JAM, et al.The effectiveness of exercise therapy in patients with osteoarthritis of the hip or knee: a randomized clinical trial. Journal of Rheumatology 1998;25: 2432-9.

\section{References to studies excluded from this review}

Abbott 2012 \{published data only\}

Abbott JH, Pinto D, Robertson MC. Exercise therapy, manual therapy, or both, for management of osteoarthritis of the hip or knee: economic evaluation alongside a randomized clinical trial. Value in Health 2012;15:A447.

Angst 2001 \{published data only\}

Angst F, Aeschlimann A, Steiner W, Stuck G. Responsiveness of the WOMAC osteoarthritis index as compared with the SF-36 in patients with osteoarthritis of the legs undergoing a comprehensive rehabilitation intervention. Annals of the Rheumatic Diseases 2001;60:834-40.

\section{Boeer 2010 \{published data only\}}

Boeer J, Mueller O, Krauss I, Haupt G, Axmann D, Horstmann T. Effects of a sensory-motor exercise program for older adults with osteoarthritis or prosthesis of the hip using measurements made by the posturomed oscillatory platform. Journal of Geriatric Physical Therapy 2010;33: $10-5$.

Brantingham 2012 \{published data only\} Brantingham JW, Parkin-Smith G, Cassa TK, Globe GA, Globe D, Pollard H, et al.Full kinetic chain manual and manipulative therapy plus exercise compared with targeted manual and manipulative therapy plus exercise for symptomatic osteoarthritis of the hip: a randomized controlled trial. Archives of Physical Medicine and Rehabilitation 2012;93:259-67.

Cochrane 2005 \{published data only\}

Cochrane T, Davey RC, Matthes Edwards SM. Randomised controlled trial of the cost-effectiveness of water-based therapy for lower limb osteoarthritis. Health Technology Assessment 2005;9:1-114.
Coupe 2007 \{published data only\}

Coupe VM, Veenhof C, van Tulder MW, Dekker J, Bijlsma $\mathrm{JW}$, van den Ende $\mathrm{CH}$. The cost-effectiveness of behavioural graded activity in patients with osteoarthritis of hip and/or knee. Annals of the Rheumatic Diseases 2007;66:215-21.

de Jong 2004 \{published data only\} de Jong ORW, Hopman-Rock M, Tak E, Klazinga N. An implementation study of two evidence-based exercise and health education programmes for older adults with osteoarthritis of the knee and hip. Health Education Research 2004;19:316.

Eitzen 2011 \{published data only\}

Eitzen I, Fernandes L, Rydevik K, Nordsletten L, Risberg M. Gait characteristics and potential effect of supervised exercise therapy in hip osteoarthritis patients with mild to moderate pain. A randomized controlled trial. Osteoarthritis and Cartilage 2011;19:S17-8.

Green 1993 \{published data only\}

Green J, McKenna F, Redfern EJ, Chamberlain MA. Home exercises are as effective as outpatient hydrotherapy for osteoarthritis of the hip. British Journal of Rheumatology 1993;32:812-5.

Halbert 2001 \{published data only\} Halbert J, Crotty M, Weller D, Ahern M, Silagy C. Primary care-based physical activity programs: effectiveness in sedentary older patients with osteoarthritis symptoms. Arthritis Care and Research 2001;45:228-34.

Haslam 2001 \{published data only\} Haslam R. A comparison of acupuncture with advice and exercises on the symptomatic treatment of osteoarthritis of the hip - a randomised controlled trial. Acupuncture Medicine 2001;19:19-26.

Heuts 2005 \{published data only\} Heuts PH, de Bie R, Drietelaar M, Aretz K, Hopman-Rock $\mathrm{M}$, Bastiaenen $\mathrm{CH}$, et al.Self-management in osteoarthritis of hip or knee: a randomized clinical trial in a primary healthcare setting. Journal of Rheumatology 2005;32:543-9.

Hinman 2007 \{published data only\} Hinman RS, Heywood SE, Day AR. Aquatic physical therapy for hip and knee osteoarthritis: results of a singleblind randomized controlled trial. Physical Therapy 2007; 87:32-43.

Hoeksma 2004 \{published data only\} Hoeksma HL, Dekker J, Ronday HK, Heering A, van der Lubbe N, Vel C, et al.Comparison of manual therapy and exercise therapy in osteoarthritis of the hip: a randomized clinical trial. Arthritis Rheumatism 2004;51:722-9.

Hoeksma 2005 \{published data only\} Hoeksma HL, Dekker J, Ronday HK, Breedveld RC, van den Ende CH. Manual therapy in osteoarthritis of the hip: outcome in subgroups of patients. Rheumatology 2005;44: $461-4$.

Hoeksma 2006 \{published data only\} Hoeksma HL, van den Ende CH, Breedveld FC, Ronday HK, Dekker J. A comparison of the OARSI response 
criteria with patient's global assessment in patients with osteoarthritis of the hip treated with a non-pharmacological intervention. Osteoarthritis and Cartilage 2006;14:77-81.

\section{Klasbo 2003 \{published data only\}}

Klasbo M, Larsson G, Harmas-Ringdahl K. Promising outcome of a hip school for patients with hip dysfunction. Arthritis and Rheumatism 2003;49:321-7.

Koybashi 2010 \{published data only\}

Koybasi M, Borman P, Kocaoglu S, Ceceli E. The effect of additional therapeutic ultrasound in patients with primary hip osteoarthritis: a randomized placebo-controlled study. Clinical Rheumatology 2010;29:1387-94.

Lin 2004 \{published data only\}

Lin SY, Davey RC, Cochrane T. Community rehabilitation for older adults with osteoarthritis of the lower limb: a controlled clinical trial. Clinical Rehabilitation 2004;18: 92-101.

Pisters 2010a \{published data only\}

Pisters MF, Veenhof C, de Bakker DH, Schellevis FG, Dekker J. Behavioural graded activity results in better exercise adherence and more physical activity than usual care in people with osteoarthritis: a cluster-randomised trial. Journal of Physiotherapy 2010;56:41-7.

Pisters 2010b \{published data only\}

Pisters MF, Veenhof C, Schellevis FG, De Bakker DH, Dekker J. Long-term effectiveness of exercise therapy in patients with osteoarthritis of the hip or knee: a randomized controlled trial comparing two different physical therapy interventions. Osteoarthritis Cartilage 2010;18:1019-26.

Ravaud 2004 \{published data only\}

Ravaud P, Giraudeau B, Logeart I, Larguier JS, Rolland $\mathrm{D}$, Treves $\mathrm{R}$, et al.Management of osteoarthritis with an unsupervised home based exercise programme and/or patient administered assessment tools. A cluster randomised controlled trial with a $2 \times 2$ factorial design. Annals of the Rheumatic Diseases 2004;63:703-8.

Rooks 2006 \{published data only\}

Rooks DS, Huang J, Bierbaum BE, Bolus SA, Rubano J, Connolly CE, et al.Effect of preoperative exercise on measures of functional status in men and women undergoing total hip and knee arthroplasty. Arthritis and Rheumatism 2006;55:700-8.

Song 2010 \{published data only\} Song R, Roberts BL, Lee E, Lam P, Bae SC. A randomized study of the effects of t'ai chi on muscle strength, bone mineral density, and fear of falling in women with osteoarthritis. Journal of Alternative and Complementary Medicine 2010;3:227-33.

Steenstrup 2012 \{published data only\}

Steenstrup B, Roudesli M, Beaufils J. Evaluation of a specific protocol of ambulatory physiotherapy for hip osteoarthritis [Evaluation d'un protocole specifique de kinesitherapie ambulatoire de la coxarthrose]. Kinesitherapie 2012;12: 67-77.
Steinhilber 2012 \{published data only\}

Steinhilber B, Haupt G, Miller R, Boeer J, Grau S, Janssen $\mathrm{P}$, et al.Feasibility and efficacy of an 8 -week progressive home-based strengthening exercise program in patients with osteoarthritis of the hip and/or total hip joint replacement: a preliminary trial. Clinical Rheumatology 2012;31:511-9.

Stener-Victoria 2004 \{published data only\}

Stener-Victoria E, Kruse C, Jung K. Comparison between electro-acupuncture and hydrotherapy, both in combination with patient education and patient education alone, on the symptomatic treatment of osteoarthritis of the hip. Clinical Journal of Pain 2004;20:179-85.

Svege 2010 \{published data only\}

Svege IC, Fernandes L, Nordsletten L, Risberg M. Long term effect of a supervised exercise program and patient education for patients with hip osteoarthritis. A randomized controlled trial. Osteoarthritis and Cartilage 2010;18:S142.

Svege 2011 \{published data only\}

Svege IC, Fernandes L, Nordsletten L, Risberg M. Time to total hip replacement surgery after supervised exercise and patient education in patients with hip osteoarthritis. A randomized intervention study with between 3.5 and 6 years follow up. Osteoarthritis and Cartilage 2011;19:S44-5.

Sylvester 1989 \{published data only\}

Sylvester KL. Investigation of the effect of hydrotherapy in the treatment of osteoarthritic hips. Clinical Rehabilitation 1989;4:223-8.

Uesugi 2012 \{published data only\}

Uesugi Y, Koyanagi J, Nishii T, Hayashi S, Fujishiro T, Takagi K, et al.Clinical trial of step-up exercise therapy using DVD for patients with hip osteoarthritis. Osteoarthritis and Cartilage 2012;20:S265.

van Baar 2001 \{published data only\} van Baar ME, Dekker J, Oostendorp RA, Bijl D, Voorn $\mathrm{TB}, \mathrm{Bijl}$ sma JW. Effectiveness of exercise in patients with osteoarthritis of hip or knee: nine months' follow up. Annals of the Rheumatic Diseases 2001;60:1123-30.

Veenhof 2006 \{published data only\} Veenhof C, Koke AJ, Dekker J, Oostendorp RA, Bijlsma JW, van Tulder MW, et al.Effectiveness of behavioural graded activity in patients with osteoarthritis of the hip and/or knee: a randomized clinical trial. Arthritis Care and Research 2006;55:925-34.

Wang 2007 \{published data only\}

Wang T-J, Belza B, Thompson FE, Whitney JD, Bennett K. Effects of aquatic exercise on flexibility, strength and aerobic fitness in adults with osteoarthritis of the hip or knee. Journal of Advanced Nursing 2007;57:141-52.

\section{Additional references}

\section{Arden 2006}

Arden N, Nevitt MC. Osteoarthritis: epidemiology. Best Practice and Research Clinical Rheumatology 2006;20:3-25. 


\section{Arokoski 2002}

Arokoski MH, Arokoski JP, Haara M, Kankaanpaa M, Vesterinen M, Niemitukia LH, et al.Hip muscle strength and muscle cross sectional area in men with and without hip osteoarthritis. Journal of Rheumatology 2002;29:2185-95.

Bellamy 1997

Bellamy N, Kirwan J, Boers M, Brooks P, Strand V, Tugwell $\mathrm{P}$, et al.Recommendations for a core set of outcome measures for future phase III clinical trials in knee, hip and hand osteoarthritis. Consensus development at OMERACT III. Journal of Rheumatology 1997;24:799-802.

Busija 2010

Busija L, Bridgett L, Williams S, Osborne R, Buchbinder $\mathrm{R}$, March L, et al.Burden of musculoskeletal conditions: osteoarthritis. Best Practice and Research in Clinical Rheumatology 2010;24:757-69.

Cohen 1977

Cohen J. Statistical Power Analysis for the Behavioural Sciences. New York: Academic, 1977.

\section{Croft 2002}

Croft P, Lewis M, Wynn Jones C, Coggon D, Cooper C. Health status in patients awaiting hip replacement for osteoarthritis. Rheumatology 2002;41:1001-7.

\section{Dawson 2004}

Dawson J, Linsell L, Zondervan K, Rose R, Randall T, Carr A. Epidemiology of hip and knee pain and its impact on overall health status in older adults. Rheumatology 2004;43: 497-504.

\section{Deeks 2011}

Deeks JJ, Higgins JPT, Altman DG. Chapter 9: Analysing data and undertaking meta-analyses. In: Higgins J, Green $S$ (editors). Cochrane Handbook for Systematic Reviews of Interventions Version 5.1.0 [updated March 2011]. The Cochrane Collaboration, 2011. Available from www.cochrane-handbook.org.

\section{Fransen 2011}

Fransen M, Agaliotis M, Bridgett L, Mackey M. Hip and knee pain. Occupational risk factors. Best Practice and Research in Clinical Rheumatology 2011;25:81-101.

\section{Hernandez-Molina 2008}

Hernandez-Molina G, Reichenbach S, Zhang B, Lavalley M, Felson DT. Effect of therapeutic exercise for hip osteoarthritis pain: results of a meta-analysis. Arthritis and Rheumatism 2008;59:1221-8.

\section{Juni 2006}

Juni P, Reichenbach S, Dieppe P. Osteoarthritis: Rational approach to treating the individual. Best Practice \& Research in Clinical Rheumatology 2006;20:721-40.

Lane 2007

Lane NE. Osteoarthritis of the hip. New England Journal of Medicine 2007;357:1413-21.

Lawrence 1998

Lawrence RC, Helmick CG, Arnett FC. Estimates of the prevalence of arthritis and selected musculoskeletal disorders in the United States. Arthritis and Rheumatism 1998;41:

778-99.

\section{Moskowitz 2007}

Moskowitz RW, Altman RD, Hochberg MC, Buckwalter JA, Goldberg VM. Osteoarthritis. Diagnosis and medicall surgical management. Fourth. Philadelphia PA: Lippincott Williams \& Wilkins, 2007.

\section{Odding 1998}

Odding E, Valkenburg HA, Algra D, Vandenoweland FA, Grobbee DE, Hofman A. Associations of radiological osteoarthritis of the hip and knee with locomotor disability in the Rotterdam study. Annals of the Rheumatic Diseases 1998;57:203-8.

Reichenbach 2007

Reichenbach S, Sterchi R, Scherer M, Trelle S, Burgi E, Burgi U, et al.Meta-analysis: chondroitin for osteoarthritis of the knee hip. Annals of Internal Medicine 2007;146: 580-90.

RevMan 2012

The Nordic Cochrane Centre, The Cochrane Collaboration. Review Manager (RevMan). 5.2. Copenhagen: The Nordic Cochrane Centre, The Cochrane Collaboration, 2012.

\section{Schünemann 2011a}

Schünemann HJ, Oxman AD, Higgins JPT, Vist GE, Glasziou P, Guyatt GH. Chapter 11: Presenting results and 'Summary of findings' tables. In: Higgins JPT, Green S (editors). Cochrane Handbook for Systematic Reviews of Interventions Version 5.1.0 [updated March 2011]. The Cochrane Collaboration, 2011. Available from www.cochrane-handbook.org.

\section{Schünemann 2011b}

Schünemann HJ, Oxman AD, Vist GE, Higgins JPT, Deeks JJ, Glasziou P, et al.Chapter 12: Interpreting results and drawing conclusions. In: Higgins JPT, Green S (editors). Cochrane Handbook for Systematic Reviews of Interventions Version 5.1.0 [updated March 2011]. The Cochrane Collaboration, 2011. Available from www.cochrane-handbook.org.

\section{Sterne 2011}

Sterne JAC, Egger M, Moher D. Chapter 10: Addressing reporting biases. Cochrane Handbook for Systematic Reviews of Interventions. In: Higgins JPT, Green S (editors). Cochrane Handbook for Systematic Reviews of Interventions Version 5.1.0 [updated March 2011]. The Cochrane Collaboration, 2011. Available from www.cochrane-handbook.org.

\section{Suetta 2007}

Suetta C, Aagaard P, Magnusson SP, Andersen LL, Sipila S, Rosted A, et al.Muscle size, neuromuscular activation, and rapid force characteristics in elderly men and women: effects of unilateral long-term disuse due to hip osteoarthritis. Journal of Applied Physiology 2007;102:942-8.

\section{Zhang 2008}

Zhang W, Moskowitz R, Nuki G, Abramson S, Altman $\mathrm{R}$, Arden N, et al.OARSI recommendations for the 
management of hip and knee osteoarthritis, Part II: OARSI evidence-based, expert consensus guidelines. Osteoarthritis and Cartilage 2008;16:137-62.

\section{Zhang 2010}

Zhang W, Nuki G, Moskowitz RW, Abramson S, Altman $\mathrm{RD}$, Arden NK, et al.OARSI recommendations for the management of hip and knee osteoarthritis: Part III: changes in evidence following systematic cumulative update of research published through January 2009. Osteoarthritis and Cartilage 2010;18:476-99.

\section{References to other published versions of this review}

\section{Fransen 2001}

Fransen M, McConnell S, Bell M 2001. Exercise for osteoarthritis of the hip or knee. Cochrane Database of Systematic Reviews 2001, Issue 2. [DOI: 10.1002/ 14651858.CD007912]

\section{Fransen 2009}

Fransen M, McConnell S, Hernandez-Molina G,

Reichenbach S. Exercise for osteoarthritis of the hip.

Cochrane Database of Systematic Reviews 2009, Issue 3. [DOI: 10.1002/14651858.CD007912]

* Indicates the major publication for the study 


\section{CHARACTERISTICS OF STUDIES}

\section{Characteristics of included studies [ordered by study ID]}

\section{Abbott 2013}

\begin{tabular}{l|l}
\hline Methods & $\begin{array}{l}\text { Low bias risk } \\
\text { Blinded assessor } \\
\text { ITT analysis } \\
\text { Usual GP care control group }\end{array}$ \\
\hline Participants & $\begin{array}{l}\text { People with hip and knee OA } \\
\text { 4-arm RCT: manual therapy, exercise therapy, manual therapy plus exercise therapy, } \\
\text { usual GP care alone } \\
\text { 45 people with hip OA allocated to exercise or usual GP care alone groups } \\
\text { Mean age: } 66 \text { years } \\
\text { ACR clinical criteria }\end{array}$ \\
\hline Interventions & $\begin{array}{l}\text { Individually provided by physiotherapy, } 50 \text { minutes (7 weeks, } 1 \text { x per week plus } 2 \text { booster } \\
\text { sessions week } 16) \\
\text { Control: usual GP care alone }\end{array}$ \\
\hline Outcomes & $\begin{array}{l}\text { At } 1 \text { year: } \\
\text { WOMAC pain }(0-50) \\
\text { WOMAC physical function }(0-170)\end{array}$ \\
\hline Notes & $\begin{array}{l}\text { Long interval between end of monitored treatment (4 months) and outcomes assessment } \\
(1 \text { year) }\end{array}$ \\
\hline
\end{tabular}

Risk of bias

\begin{tabular}{lll}
\hline Bias & Authors' judgement & Support for judgement \\
\hline $\begin{array}{l}\text { Random sequence generation (selection } \\
\text { bias) }\end{array}$ & Low risk & Randomisation centre used \\
\hline Allocation concealment (selection bias) & Low risk & Randomisation centre used \\
\hline
\end{tabular}

Blinding of participants and personnel High risk Physiotherapists and participants aware of (performance bias)

treatment allocation

All outcomes

Blinding of outcome assessment (detection Unclear risk bias)

Self-reported outcomes

Blinded outcomes assessor, but participant self reported pain and function

Incomplete outcome data (attrition bias) Low risk All outcomes

ITT and minimal loss to follow-up (maximum: 2/51 exercise; 4/51 usual care)

Selective reporting (reporting bias)

Low risk

Registered trial protocol 


\section{Abbott 2013 (Continued)}

\begin{tabular}{|c|c|c|}
\hline Other bias & Unclear risk & $\begin{array}{l}\text { 8-month interval between end of moni- } \\
\text { tored treatment and outcomes assessment }\end{array}$ \\
\hline
\end{tabular}

Carlson 2011

\begin{tabular}{|c|c|c|}
\hline Methods & \multicolumn{2}{|l|}{ Unclear risk of bias } \\
\hline Participants & \multicolumn{2}{|c|}{$\begin{array}{l}\text { Hip only } \\
\text { Recruited from specialist clinics and the community } \\
\text { Pain at least once per week in } 1 \text { or both hips, difficulty with ADL secondary to hip pain, } \\
\text { radiographic evidence of femoral or acetabular osteophytes (or both) or axial joint space } \\
\text { narrowing and active hip flexion }<115 \text { degrees }\end{array}$} \\
\hline Interventions & \multicolumn{2}{|c|}{$\begin{array}{l}20 \text { people allocated to } 3 \text { month aerobic activity and resistance training programme ( } 45 \\
\text { minutes) } 2-3 \text { times per week, } 10 \text { people to usual care }\end{array}$} \\
\hline Outcomes & \multicolumn{2}{|c|}{$\begin{array}{l}\text { Post treatment only } \\
\text { Pain on } 0-100 \text { VAS } \\
\text { WOMAC physical function }(0-100)\end{array}$} \\
\hline Notes & \multicolumn{2}{|c|}{ No response to email request for further information } \\
\hline \multicolumn{3}{|l|}{ Risk of bias } \\
\hline Bias & Authors' judgement & Support for judgement \\
\hline $\begin{array}{l}\text { Random sequence generation (selection } \\
\text { bias) }\end{array}$ & Unclear risk & Abstract only - no information provided \\
\hline Allocation concealment (selection bias) & Unclear risk & Abstract only - no information provided \\
\hline $\begin{array}{l}\text { Blinding of participants and personnel } \\
\text { (performance bias) } \\
\text { All outcomes }\end{array}$ & High risk & Participants and personnel aware of treatment allocation \\
\hline $\begin{array}{l}\text { Blinding of outcome assessment (detection } \\
\text { bias) } \\
\text { Self-reported outcomes }\end{array}$ & Unclear risk & Abstract only - no information provided \\
\hline $\begin{array}{l}\text { Incomplete outcome data (attrition bias) } \\
\text { All outcomes }\end{array}$ & Unclear risk & Abstract only - no information provided \\
\hline Selective reporting (reporting bias) & Unclear risk & Abstract only - no information provided \\
\hline Other bias & Unclear risk & None apparent \\
\hline
\end{tabular}


Fernandes 2010

\begin{tabular}{|c|c|c|}
\hline Methods & \multicolumn{2}{|c|}{$\begin{array}{l}\text { Low bias risk } \\
\text { Blinded assessor } \\
\text { No loss to follow-up at } 4 \text { months } \\
\text { Patient education only control ('Hip School') }\end{array}$} \\
\hline Participants & \multicolumn{2}{|c|}{$\begin{array}{l}\text { *Hip OA only } \\
109 \text { people with hip pain }>3 \text { months and HHS } 60-95 \\
\text { Mean age } 58 \text { years } \\
\text { Radiographic criteria: joint space width }<4 \mathrm{~mm}\end{array}$} \\
\hline Interventions & \multicolumn{2}{|c|}{$\begin{array}{l}\text { Individually based, clinic } 12 \text { weeks ( } 2 \text { x per week) } \\
\text { Treatment: mixed - strengthening, functional, flexibility }\end{array}$} \\
\hline Outcomes & \multicolumn{2}{|c|}{$\begin{array}{l}\text { At } 4 \text { months: } \\
\text { WOMAC Pain }(0-100) \\
\text { WOMAC Physical Function }(0-100)\end{array}$} \\
\hline Notes & \multicolumn{2}{|c|}{ About $20 \%$ loss to follow-up at 10 months } \\
\hline \multicolumn{3}{|l|}{ Risk of bias } \\
\hline Bias & Authors' judgement & Support for judgement \\
\hline $\begin{array}{l}\text { Random sequence generation (selection } \\
\text { bias) }\end{array}$ & Low risk & Computer generated, blocks of 10 \\
\hline Allocation concealment (selection bias) & Low risk & $\begin{array}{l}\text { Independent researcher, sealed numbered } \\
\text { envelopes }\end{array}$ \\
\hline $\begin{array}{l}\text { Blinding of participants and personnel } \\
\text { (performance bias) } \\
\text { All outcomes }\end{array}$ & High risk & $\begin{array}{l}\text { Physiotherapists and participants aware of } \\
\text { treatment allocation }\end{array}$ \\
\hline $\begin{array}{l}\text { Blinding of outcome assessment (detection } \\
\text { bias) } \\
\text { Self-reported outcomes }\end{array}$ & Unclear risk & $\begin{array}{l}\text { Blinded outcomes assessor, but participant } \\
\text { self reported pain and function }\end{array}$ \\
\hline $\begin{array}{l}\text { Incomplete outcome data (attrition bias) } \\
\text { All outcomes }\end{array}$ & Low risk & $\begin{array}{l}\text { Only } 1 \text { person lost to follow-up at } 4 \text { months } \\
\text { ( } 20 \text { people lost at } 10 \text { months) }\end{array}$ \\
\hline Selective reporting (reporting bias) & Low risk & $\begin{array}{l}\text { Main outcomes specified a priori - } \\
\text { WOMAC pain }\end{array}$ \\
\hline Other bias & Low risk & None apparent \\
\hline
\end{tabular}


Foley 2003

\begin{tabular}{|c|c|c|}
\hline Methods & \multicolumn{2}{|l|}{$\begin{array}{l}\text { Low bias risk } \\
\text { Blinded assessor } \\
\text { ITT analysis } \\
\text { Waiting list }\end{array}$} \\
\hline Participants & \multicolumn{2}{|c|}{$\begin{array}{l}\text { People with hip and knee OA recruited } \\
29 \text { mostly clinic patients with hip OA } \\
\text { Mean age: } 70 \text { years } \\
\text { Radiographic criteria }\end{array}$} \\
\hline Interventions & \multicolumn{2}{|c|}{$\begin{array}{l}\text { Class-based ( } 6 \text { weeks) } \\
\text { Treatment: } 18 \text { x strengthening, ROM, 30-minute classes } \\
\text { Control: telephone call every } 2 \text { weeks }\end{array}$} \\
\hline Outcomes & \multicolumn{2}{|c|}{$\begin{array}{l}\text { At } 6 \text { weeks: } \\
\text { WOMAC pain }(0-20) \\
\text { WOMAC function }(0-68) \\
\text { Unable to obtain SF-12 MCS data specific for people with hip OA for the updated } \\
\text { review }\end{array}$} \\
\hline Notes & \multicolumn{2}{|c|}{ Separate analysis per hip OA, gym-based group vs. controls } \\
\hline \multicolumn{3}{|l|}{ Risk of bias } \\
\hline Bias & Authors' judgement & Support for judgement \\
\hline $\begin{array}{l}\text { Random sequence generation (selection } \\
\text { bias) }\end{array}$ & Low risk & Computer generated \\
\hline Allocation concealment (selection bias) & Low risk & Central allocation \\
\hline $\begin{array}{l}\text { Blinding of participants and personnel } \\
\text { (performance bias) } \\
\text { All outcomes }\end{array}$ & High risk & $\begin{array}{l}\text { Participants and personnel aware of treat- } \\
\text { ment allocation }\end{array}$ \\
\hline $\begin{array}{l}\text { Blinding of outcome assessment (detection } \\
\text { bias) } \\
\text { Self-reported outcomes }\end{array}$ & Unclear risk & $\begin{array}{l}\text { Blinded outcomes assessor, but participant } \\
\text { self reported pain and function }\end{array}$ \\
\hline $\begin{array}{l}\text { Incomplete outcome data (attrition bias) } \\
\text { All outcomes }\end{array}$ & Low risk & $\begin{array}{l}\text { Small numbers lost to follow-up, balanced } \\
\text { between allocation groups }\end{array}$ \\
\hline Selective reporting (reporting bias) & Unclear risk & Unable to ascertain \\
\hline Other bias & Unclear risk & About $40 \%$ on orthopaedic waiting list \\
\hline
\end{tabular}




\begin{tabular}{|c|c|}
\hline Methods & $\begin{array}{l}\text { Low bias risk } \\
\text { Blinded assessor } \\
\text { ITT analysis } \\
\text { Waiting list }\end{array}$ \\
\hline Participants & $\begin{array}{l}\text { People with hip and knee OA recruited } \\
20 \text { community volunteers hip OA } \\
75 \% \text { female } \\
\text { Mean age: } 70 \text { years } \\
\text { ACR criteria }\end{array}$ \\
\hline Interventions & $\begin{array}{l}\text { Class-based ( } 12 \text { weeks) } \\
\text { Treatment: } 24 \mathrm{x} \text { tai chi classes, } 60 \text {-minute classes } \\
\text { Control: waiting list }\end{array}$ \\
\hline Outcomes & $\begin{array}{l}\text { At } 12 \text { weeks: } \\
\text { WOMAC pain }(0-100) \\
\text { WOMAC function }(0-100) \\
\text { SF-MCS }\end{array}$ \\
\hline Notes & $\begin{array}{l}\text { Disaggregated analysis (hip or knee OA) according to identified signal (most painful) } \\
\text { joint }\end{array}$ \\
\hline
\end{tabular}

\section{Risk of bias}

\begin{tabular}{|c|c|c|}
\hline Bias & Authors' judgement & Support for judgement \\
\hline $\begin{array}{l}\text { Random sequence generation (selection } \\
\text { bias) }\end{array}$ & Low risk & Random numbers table \\
\hline Allocation concealment (selection bias) & Low risk & Central allocation by administrator \\
\hline $\begin{array}{l}\text { Blinding of participants and personnel } \\
\text { (performance bias) } \\
\text { All outcomes }\end{array}$ & High risk & $\begin{array}{l}\text { Participants and personnel aware of treat- } \\
\text { ment allocation }\end{array}$ \\
\hline $\begin{array}{l}\text { Blinding of outcome assessment (detection } \\
\text { bias) } \\
\text { Self-reported outcomes }\end{array}$ & Unclear risk & $\begin{array}{l}\text { Blinded outcomes assessor, but participant } \\
\text { self reported pain and function }\end{array}$ \\
\hline $\begin{array}{l}\text { Incomplete outcome data (attrition bias) } \\
\text { All outcomes }\end{array}$ & Low risk & ITT analysis \\
\hline Selective reporting (reporting bias) & Low risk & Trial registered NCT00123994 \\
\hline Other bias & Low risk & None apparent \\
\hline
\end{tabular}


French 2013

\begin{tabular}{|c|c|c|}
\hline Methods & \multicolumn{2}{|l|}{$\begin{array}{l}\text { Low risk bias } \\
\text { Blind assessor } \\
\text { ITT analysis } \\
\text { Waiting list control }\end{array}$} \\
\hline Participants & \multicolumn{2}{|c|}{$\begin{array}{l}\text { *Hip OA only recruited (ACR clinical and radiographic criteria) } \\
88 \text { people (exercise or control) referred for physiotherapy by GPs or hospital consultants } \\
\text { Mean age: } 65 \text { years }\end{array}$} \\
\hline Interventions & \multicolumn{2}{|c|}{$\begin{array}{l}\text { Individually provided 'standardised' exercise programme }(8 \times 30 \text {-minute sessions over } \\
8 \text { weeks) plus daily home exercise programme (aerobic walking/cycling/swimming } 30 \\
\text { minutes) } \\
\text { Treatment: strengthening, flexibility, aerobic }\end{array}$} \\
\hline Outcomes & \multicolumn{2}{|c|}{$\begin{array}{l}\text { At } 9 \text { weeks: } \\
\text { Pain on activity }(0-10 \text { NRS) } \\
\text { WOMAC Physical Function (0-68) } \\
\text { SF-12 MCS }\end{array}$} \\
\hline Notes & \multicolumn{2}{|c|}{$\begin{array}{l}\text { Low-intensity programme }-8 \times 30 \text { minutes monitored only. Unclear why WOMAC } \\
\text { pain not used as primary outcome }\end{array}$} \\
\hline \multicolumn{3}{|l|}{ Risk of bias } \\
\hline Bias & Authors' judgement & Support for judgement \\
\hline $\begin{array}{l}\text { Random sequence generation (selection } \\
\text { bias) }\end{array}$ & Low risk & Computer-generated sequence \\
\hline Allocation concealment (selection bias) & Low risk & Off-site randomisation \\
\hline $\begin{array}{l}\text { Blinding of participants and personnel } \\
\text { (performance bias) } \\
\text { All outcomes }\end{array}$ & High risk & $\begin{array}{l}\text { Participants and personnel aware of treat- } \\
\text { ment allocation }\end{array}$ \\
\hline $\begin{array}{l}\text { Blinding of outcome assessment (detection } \\
\text { bias) } \\
\text { Self-reported outcomes }\end{array}$ & Unclear risk & $\begin{array}{l}\text { Blinded outcomes assessor, but participant } \\
\text { self reported pain and function }\end{array}$ \\
\hline $\begin{array}{l}\text { Incomplete outcome data (attrition bias) } \\
\text { All outcomes }\end{array}$ & Low risk & $\begin{array}{l}\text { Multiple imputations, only } 3 \text { people lost to } \\
\text { follow-up at } 9 \text { weeks }\end{array}$ \\
\hline Selective reporting (reporting bias) & Low risk & Protocol published \\
\hline Other bias & Low risk & None apparent \\
\hline
\end{tabular}


Hopman-Rock 2000

\begin{tabular}{|c|c|c|}
\hline Methods & \multicolumn{2}{|l|}{$\begin{array}{l}\text { Moderate bias risk } \\
\text { Blind assessor } \\
\text { Efficacy analysis } \\
\text { Waiting list }\end{array}$} \\
\hline Participants & \multicolumn{2}{|c|}{$\begin{array}{l}\text { Hip and knee OA recruited (ACR criteria) } \\
28 \text { volunteers hip OA, } 80 \% \text { female } \\
\text { Mean age: } 65 \text { years }\end{array}$} \\
\hline Interventions & \multicolumn{2}{|c|}{$\begin{array}{l}\text { Class-based }(6 \text { weeks }) \\
\text { Treatment: } 6 \text { x education }+ \text { exercise, } 60 \text {-minute classes }\end{array}$} \\
\hline Outcomes & \multicolumn{2}{|c|}{$\begin{array}{l}\text { At } 6 \text { weeks: } \\
\text { VAS pain (2) } \\
\text { IRGL mobility (7-28) } \\
\text { Unable to obtain quality of life data specific for people with hip OA for the updated } \\
\text { review }\end{array}$} \\
\hline Notes & \multicolumn{2}{|c|}{ Short programme. Only 6 supervised treatment occasions } \\
\hline \multicolumn{3}{|l|}{ Risk of bias } \\
\hline Bias & Authors' judgement & Support for judgement \\
\hline $\begin{array}{l}\text { Random sequence generation (selection } \\
\text { bias) }\end{array}$ & Unclear risk & Not reported \\
\hline Allocation concealment (selection bias) & Unclear risk & Not reported \\
\hline $\begin{array}{l}\text { Blinding of participants and personnel } \\
\text { (performance bias) } \\
\text { All outcomes }\end{array}$ & High risk & $\begin{array}{l}\text { Participants and personnel aware of treat- } \\
\text { ment allocation }\end{array}$ \\
\hline $\begin{array}{l}\text { Blinding of outcome assessment (detection } \\
\text { bias) } \\
\text { Self-reported outcomes }\end{array}$ & Unclear risk & $\begin{array}{l}\text { Blinded outcomes assessor, but participant } \\
\text { self reported pain and function }\end{array}$ \\
\hline $\begin{array}{l}\text { Incomplete outcome data (attrition bias) } \\
\text { All outcomes }\end{array}$ & Unclear risk & Efficacy analysis \\
\hline Selective reporting (reporting bias) & Unclear risk & Insufficient information \\
\hline Other bias & Low risk & None apparent \\
\hline
\end{tabular}


Juhakoski 2011

\begin{tabular}{|c|c|}
\hline Methods & $\begin{array}{l}\text { Low bias risk } \\
\text { Blinded assessor } \\
\text { ITT analysis } \\
\text { GP care control group }\end{array}$ \\
\hline Participants & $\begin{array}{l}{ }^{*} \text { Hip OA only } \\
\text { Community volunteers } \\
\text { Mean age: } 66 \text { years } \\
\text { About } 80 \% \text { overweight or obese } \\
\text { ACR clinical criteria } \\
\text { K\&L } 1-2(85 \%)\end{array}$ \\
\hline Interventions & $\begin{array}{l}\text { Exercise and GP care } \\
\text { Class-based ( } 12 \text { weeks) } 45 \text { minutes x } 12 \text { weekly sessions }+4 \text { booster sessions } 1 \text { year later } \\
\text { Strengthening (with maximal effort) }\end{array}$ \\
\hline Outcomes & $\begin{array}{l}3 \text { months/6 months } \\
\text { WOMAC Pain }(0-100) \\
\text { WOMAC Physical Function }(0-100)\end{array}$ \\
\hline Notes & $\begin{array}{l}\text { Both groups access to physiotherapy (as part of GP care); however, only mean sum of } \\
\text { visits over } 24 \text { months of } 1.3 \text { (active group) vs. } 2.0 \text { (control group). WOMAC scores } \\
\text { 'adjusted' for baseline differences in outcome measures, age, gender, radiological score, } \\
\text { comorbidities, existence of knee OA or knee pain (or both) and duration of hip symptoms }\end{array}$ \\
\hline
\end{tabular}

\section{Risk of bias}

\begin{tabular}{l|l|l}
\hline Bias & Authors' judgement & Support for judgement \\
\hline $\begin{array}{l}\text { Random sequence generation (selection } \\
\text { bias) }\end{array}$ & Low risk & Computer generated \\
\hline $\begin{array}{l}\text { Allocation concealment (selection bias) } \\
\text { Blinding of participants and personnel } \\
\text { (performance bias) } \\
\text { All outcomes }\end{array}$ & Ligh risk & Sealed envelopes, offsite randomisation \\
\hline $\begin{array}{l}\text { Blinding of outcome assessment (detection } \\
\text { bias) } \\
\text { Self-reported outcomes }\end{array}$ & Unclear risk & $\begin{array}{l}\text { Participants and personnel aware of treat- } \\
\text { ment allocation }\end{array}$ \\
\hline $\begin{array}{l}\text { Incomplete outcome data (attrition bias) } \\
\text { All outcomes }\end{array}$ & Low risk & $\begin{array}{l}\text { Blinded outcomes assessor, but participant } \\
\text { self reported pain and function }\end{array}$ \\
\hline \begin{tabular}{l} 
Selective reporting (reporting bias) \\
\hline
\end{tabular} & Unclear risk & $\begin{array}{l}\text { ITT, last observation carried forward, min- } \\
\text { imal loss to follow-up } \\
\text { months) }\end{array}$ \\
\hline
\end{tabular}


Juhakoski 2011 (Continued)

\begin{tabular}{|c|c|c|}
\hline Other bias & Low risk & None apparent \\
\hline
\end{tabular}

Tak 2005

\begin{tabular}{ll}
\hline Methods & $\begin{array}{l}\text { Moderate bias risk } \\
\text { Blinded assessor } \\
\text { Efficacy analysis } \\
\text { Waiting list }\end{array}$ \\
\hline Participants & *Hip OA only \\
& 109 community volunteers \\
& $\begin{array}{l}\text { Mean age: } 68 \text { years } \\
\text { Clinical ACR criteria } \\
\text { Clinical criteria OA hip }\end{array}$ \\
\hline Interventions & Class-based (8 weeks) \\
& Treatment: 8 x strengthening + home programme, 60-minute classes \\
\hline Outcomes & At 8 weeks: \\
& VAS pain $(0-10)$ \\
GARS function (18-72) \\
Generic quality of life (0-10)
\end{tabular}

\section{Risk of bias}

\begin{tabular}{ll} 
Bias Authors' judgement \\
\hline
\end{tabular}

Support for judgement

Random sequence generation (selection Low risk bias)

\begin{tabular}{|c|c|c|}
\hline Allocation concealment (selection bias) & Unclear risk & Not reported \\
\hline $\begin{array}{l}\text { Blinding of participants and personnel } \\
\text { (performance bias) } \\
\text { All outcomes }\end{array}$ & High risk & $\begin{array}{l}\text { Participants and personnel aware of treat- } \\
\text { ment allocation }\end{array}$ \\
\hline $\begin{array}{l}\text { Blinding of outcome assessment (detection } \\
\text { bias) } \\
\text { Self-reported outcomes }\end{array}$ & Unclear risk & $\begin{array}{l}\text { Blinded outcomes assessor, but participant } \\
\text { self reported pain and function }\end{array}$ \\
\hline $\begin{array}{l}\text { Incomplete outcome data (attrition bias) } \\
\text { All outcomes }\end{array}$ & High risk & $\begin{array}{l}\text { Efficacy analysis, } 36 \% \text { and } 28 \% \text { missing } \\
\text { data for pain outcome }\end{array}$ \\
\hline Selective reporting (reporting bias) & Unclear risk & Not registered \\
\hline
\end{tabular}


Tak 2005 (Continued)

\begin{tabular}{|c|c|c|}
\hline Other bias & Low risk & None apparent \\
\hline \multicolumn{3}{|l|}{ van Baar 1998} \\
\hline Methods & $\begin{array}{l}\text { Low bias risk } \\
\text { Blinded assessor } \\
\text { ITT analysis } \\
\text { Control: GP education }\end{array}$ & \\
\hline Participants & $\begin{array}{l}\text { Hip and knee OA recruited } \\
81 \text { people from GP clinic with hip OA } \\
79 \% \text { female } \\
\text { Mean age: } 68 \text { years } \\
\text { ACR criteria }\end{array}$ & \\
\hline Interventions & $\begin{array}{l}\text { Individual programme ( } 12 \text { weeks) } \\
\text { Treatment: } 17 \text { x physiotherapy ( } 30-\mathrm{min}\end{array}$ & sessions) + GP education \\
\hline Outcomes & $\begin{array}{l}\text { At } 12 \text { weeks: } \\
\text { Pain (VAS x 1) (0-100) } \\
\text { Function IRGL (7-28) }\end{array}$ & \\
\hline Notes & $\begin{array}{l}\text { Separate results provided for hip OA. M } \\
\text { had symptom duration }<1 \text { year }\end{array}$ & y early disease as approximately $50 \%$ sample \\
\hline
\end{tabular}

\section{Risk of bias}

\begin{tabular}{|c|c|c|}
\hline Bias & Authors' judgement & Support for judgement \\
\hline $\begin{array}{l}\text { Random sequence generation (selection } \\
\text { bias) }\end{array}$ & Low risk & Random numbers table \\
\hline Allocation concealment (selection bias) & Low risk & $\begin{array}{l}\text { Sealed opaque envelopes, sequential num- } \\
\text { bering for audit trail }\end{array}$ \\
\hline $\begin{array}{l}\text { Blinding of participants and personnel } \\
\text { (performance bias) } \\
\text { All outcomes }\end{array}$ & High risk & $\begin{array}{l}\text { Participants and personnel aware of treat- } \\
\text { ment allocation }\end{array}$ \\
\hline $\begin{array}{l}\text { Blinding of outcome assessment (detection } \\
\text { bias) } \\
\text { Self-reported outcomes }\end{array}$ & Unclear risk & $\begin{array}{l}\text { Blinded outcomes assessor, but participant } \\
\text { self reported pain and function }\end{array}$ \\
\hline $\begin{array}{l}\text { Incomplete outcome data (attrition bias) } \\
\text { All outcomes }\end{array}$ & Low risk & ITT analysis \\
\hline Selective reporting (reporting bias) & Unclear risk & Not registered \\
\hline
\end{tabular}




$\begin{array}{lll}\text { Other bias } & \text { Low risk } & \text { None apparent }\end{array}$

ACR: American College of Rheumatology; ADL: activities of daily living; GARS: Groningen Activity Restriction Scale; GP: general practitioner; HHS: Harris Hip Score; IRGL: Influence of Rheumatic Diseases on General Health and Lifestyle; ITT: intention to treat; K\&L: Kellgren and Lawrence; MCS: Mental Component Summary; NRS: Numerical Rating Scale; OA: osteoarthritis; RCT: randomised controlled trial; ROM: range of motion; SF: Short Form; SF-12: 12-item Short Form; WOMAC: Western Ontario and McMaster Universities Osteoarthritis Index; VAS: visual analogue scale.

\section{Characteristics of excluded studies [ordered by study ID]}

\begin{tabular}{|c|c|}
\hline Study & Reason for exclusion \\
\hline Abbott 2012 & Health economic evaluation only, abstract \\
\hline Angst 2001 & No control group \\
\hline Boeer 2010 & No non-exercise group, all participated in 'Hip School' \\
\hline Brantingham 2012 & $\begin{array}{l}\text { No non-exercise group. RCT comparing } 2 \text { different manual and manipulative therapy techniques in addition } \\
\text { to exercise }\end{array}$ \\
\hline Cochrane 2005 & No land-based exercise group \\
\hline Coupe 2007 & Supplementary analysis Veenhof 2006 \\
\hline de Jong 2004 & No non-exercise control group \\
\hline Eitzen 2011 & Supplementary analysis Fernandes 2010. Predictive study using gait characteristics \\
\hline Green 1993 & No appropriate control. Assessed added benefit of hydrotherapy to home exercises \\
\hline Halbert 2001 & Physical activity advice/recommendation only \\
\hline Haslam 2001 & $\begin{array}{l}\text { Advice and exercise was the control group } \\
\text { The evaluated treatment was acupuncture }\end{array}$ \\
\hline Heuts 2005 & Arthritis self management education programme with no supervised exercise sessions \\
\hline Hinman 2007 & No land-based exercise group \\
\hline Hoeksma 2004 & No non-exercise control. Manual therapy vs. exercise \\
\hline Hoeksma 2005 & Supplementary analysis of Hoeksma 2004 \\
\hline
\end{tabular}


(Continued)

\begin{tabular}{|c|c|}
\hline Hoeksma 2006 & Supplementary analysis of Hoeksma 2004 \\
\hline Klasbo 2003 & Education sessions with on therapeutic exercise advice \\
\hline Koybashi 2010 & No non-exercise control \\
\hline Lin 2004 & No land-based exercise group \\
\hline Pisters $2010 \mathrm{a}$ & $\begin{array}{l}\text { No non-exercise group. Both treatment allocation were supervised by physiotherapists and involved exercise- } \\
\text { focused programmes }\end{array}$ \\
\hline Pisters $2010 \mathrm{~b}$ & $\begin{array}{l}\text { No non-exercise group. Both treatment allocation were supervised by physiotherapists and involved exercise- } \\
\text { focused programmes }\end{array}$ \\
\hline Ravaud 2004 & Cluster randomised trial, unsupervised exercise and all participants prescribed daily Vioxx \\
\hline Rooks 2006 & Peri-operative exercise programme \\
\hline Song 2010 & Suspect focus on people with knee osteoarthritis; however, site of symptomatic osteoarthritis not specified \\
\hline Steenstrup 2012 & $\begin{array}{l}\text { Limited exercise involved (only } 10 \mathrm{x} \text { a single hip abduction exercise). The physiotherapy involved mostly } \\
\text { manual therapy plus electrotherapy }\end{array}$ \\
\hline Steinhilber 2012 & Included people with total hip replacement \\
\hline Stener-Victoria 2004 & No land-based exercise group \\
\hline Svege 2010 & Supplementary analysis of Fernandes 2010 \\
\hline Svege 2011 & Supplementary analysis of Fernandes 2010 \\
\hline Sylvester 1989 & No appropriate control. Hydrotherapy compared with exercises plus shortwave diathermy (14 people) \\
\hline Uesugi 2012 & Evaluating 2 delivery modes (DVD or written materials) of same exercise programme \\
\hline van Baar 2001 & Secondary analysis van Baar 1998 (follow-up study) \\
\hline Veenhof 2006 & $\begin{array}{l}\text { No non-exercise control. Both treatment allocations (behavioural graded activity or usual physiotherapy care) } \\
\text { were supervised by physiotherapists and involved exercise-focused programmes }\end{array}$ \\
\hline Wang 2007 & No land-based exercise group \\
\hline
\end{tabular}


DATA AND ANALYSES

Comparison 1. Immediate post treatment

\begin{tabular}{lccll} 
Outcome or subgroup title & $\begin{array}{c}\text { No. of } \\
\text { studies }\end{array}$ & $\begin{array}{c}\text { No. of } \\
\text { participants }\end{array}$ & \multicolumn{1}{c}{ Statistical method } & Effect size \\
\hline 1 Pain & 9 & 549 & Std. Mean Difference (IV, Random, 95\% CI) & $-0.38[-0.55,-0.20]$ \\
$\quad$ 1.1 End of treatment scores & 8 & 519 & Std. Mean Difference (IV, Random, 95\% CI) & $-0.38[-0.55,-0.20]$ \\
1.2 Change scores & 1 & 30 & Std. Mean Difference (IV, Random, 95\% CI) & $-0.36[-1.12,0.41]$ \\
2 Physical function & 9 & 521 & Std. Mean Difference (IV, Random, 95\% CI) & $-0.30[-0.54,-0.05]$ \\
2.1 End of treatment scores & 6 & 401 & Std. Mean Difference (IV, Random, 95\% CI) & $-0.33[-0.53,-0.13]$ \\
2.2 Change scores & 3 & 120 & Std. Mean Difference (IV, Random, 95\% CI) & $-0.20[-0.96,0.55]$ \\
3 Quality of life & 3 & & Std. Mean Difference (IV, Random, 95\% CI) & Subtotals only \\
$\quad$ 3.1 End of treatment scores & 3 & 183 & Std. Mean Difference (IV, Random, 95\% CI) & $0.07[-0.23,0.36]$ \\
4 Study withdrawals & 7 & 715 & Risk Difference (M-H, Random, 95\% CI) & $0.01[-0.01,0.04]$ \\
\hline
\end{tabular}

Comparison 2. Sustainability (three to six months)

\begin{tabular}{ccclc} 
Outcome or subgroup title & $\begin{array}{c}\text { No. of } \\
\text { studies }\end{array}$ & $\begin{array}{c}\text { No. of } \\
\text { participants }\end{array}$ & Statistical method & Effect size \\
\hline 1 Pain & 5 & 391 & Std. Mean Difference (IV, Random, 95\% CI) & $-0.38[-0.58,-0.18]$ \\
1.1 End of treatment & 4 & 326 & Std. Mean Difference (IV, Random, 95\% CI) & $-0.39[-0.61,-0.17]$ \\
1.2 Change scores & 1 & 65 & Std. Mean Difference (IV, Random, 95\% CI) & $-0.34[-0.83,0.15]$ \\
2 Physical function & 5 & 365 & Std. Mean Difference (IV, Random, 95\% CI) & $-0.37[-0.57,-0.16]$ \\
2.1 End of treatment & 4 & 300 & Std. Mean Difference (IV, Random, 95\% CI) & $-0.43[-0.66,-0.20]$ \\
2.2 Change scores & 1 & 65 & Std. Mean Difference (IV, Random, 95\% CI) & $-0.07[-0.56,0.42]$ \\
\hline
\end{tabular}

Comparison 3. Hip osteoarthritis (OA) versus hip/knee OA studies

\begin{tabular}{ccccc} 
Outcome or subgroup title & $\begin{array}{c}\text { No. of } \\
\text { studies }\end{array}$ & $\begin{array}{c}\text { No. of } \\
\text { participants }\end{array}$ & Statistical method & Effect size \\
\hline 1 Pain post treatment & 9 & 549 & Std. Mean Difference (IV, Random, 95\% CI) & $-0.38[-0.55,-0.20]$ \\
1.1 Hip OA only & 5 & 419 & Std. Mean Difference (IV, Random, 95\% CI) & $-0.30[-0.49,-0.10]$ \\
1.2 Hip/knee OA & 4 & 130 & Std. Mean Difference (IV, Random, 95\% CI) & $-0.66[-1.02,-0.29]$ \\
2 Physical function post treatment & 9 & 521 & Std. Mean Difference (IV, Random, 95\% CI) & $-0.30[-0.54,-0.05]$ \\
2.1 Hip OA only & 5 & 393 & Std. Mean Difference (IV, Random, 95\% CI) & $-0.35[-0.57,-0.13]$ \\
2.2 Hip/knee OA & 4 & 128 & Std. Mean Difference (IV, Random, 95\% CI) & $-0.20[-0.79,0.40]$ \\
\hline
\end{tabular}

Exercise for osteoarthritis of the hip (Review) 


\section{Analysis I.I. Comparison I Immediate post treatment, Outcome I Pain.}

Review: Exercise for osteoarthritis of the hip

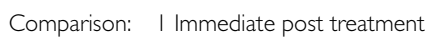

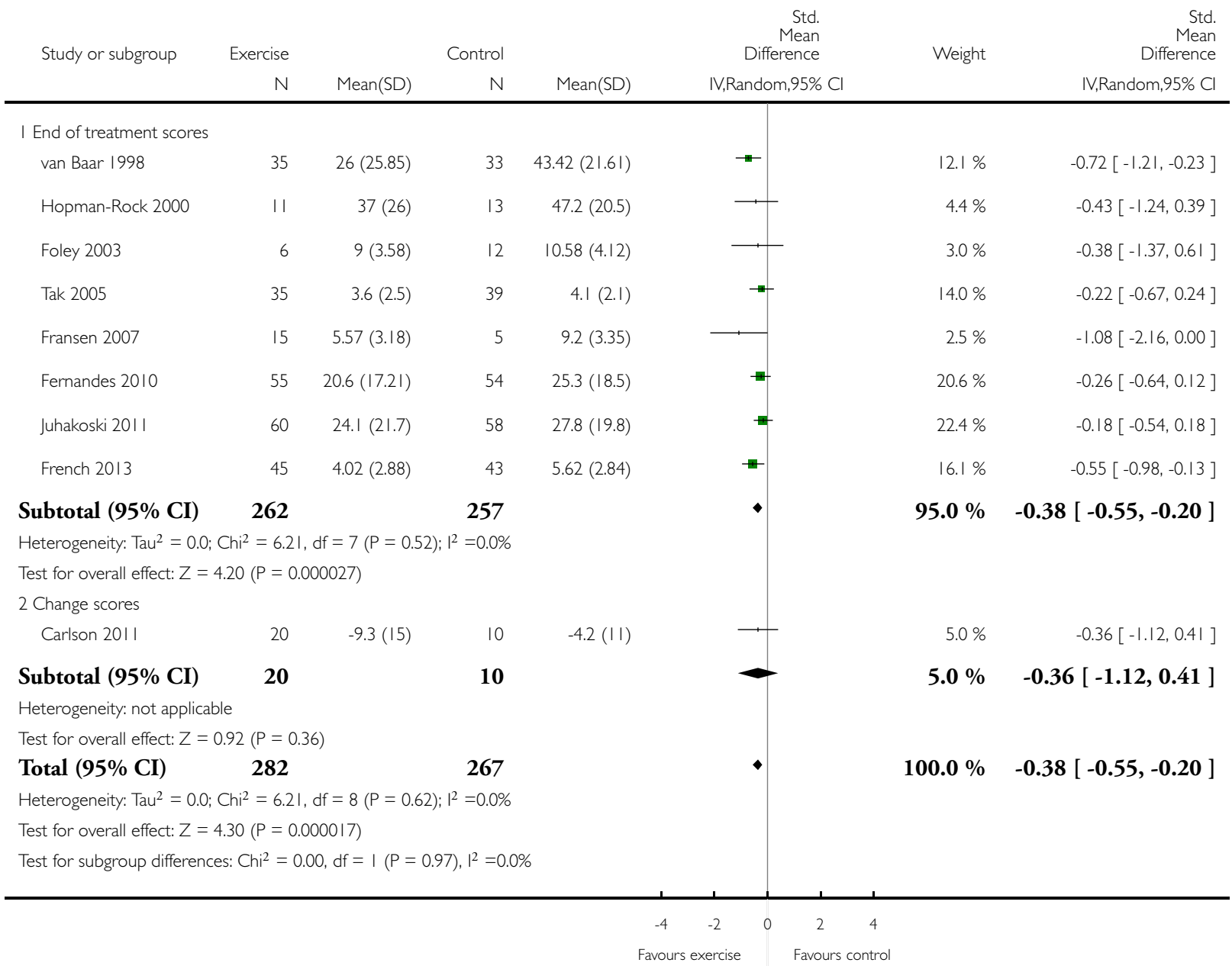




\section{Analysis I.2. Comparison I Immediate post treatment, Outcome 2 Physical function.}

Review: Exercise for osteoarthritis of the hip

Comparison: I Immediate post treatment

Outcome: 2 Physical function

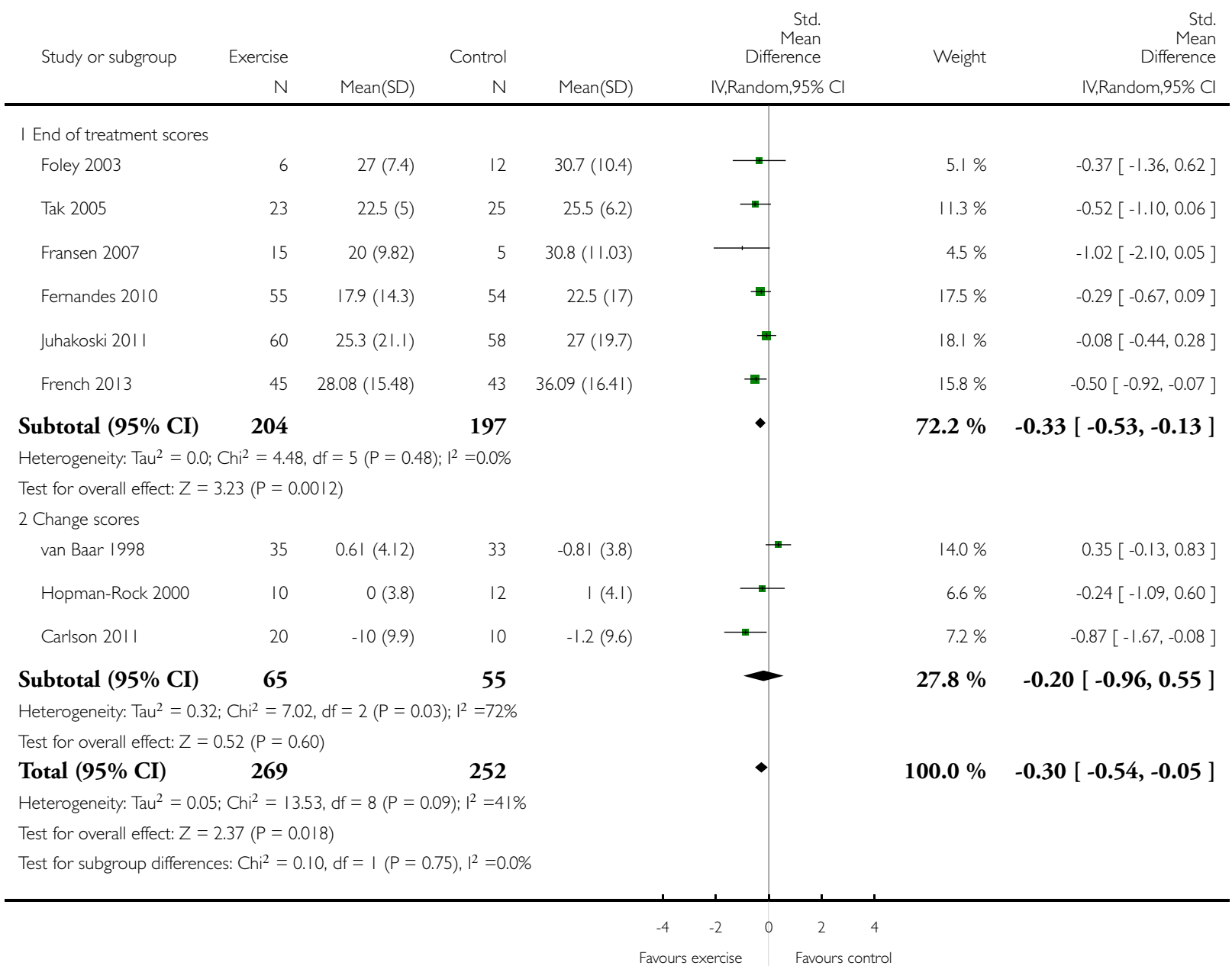




\section{Analysis I.3. Comparison I Immediate post treatment, Outcome 3 Quality of life.}

Review: Exercise for osteoarthritis of the hip

Comparison: I Immediate post treatment

Outcome: 3 Quality of life

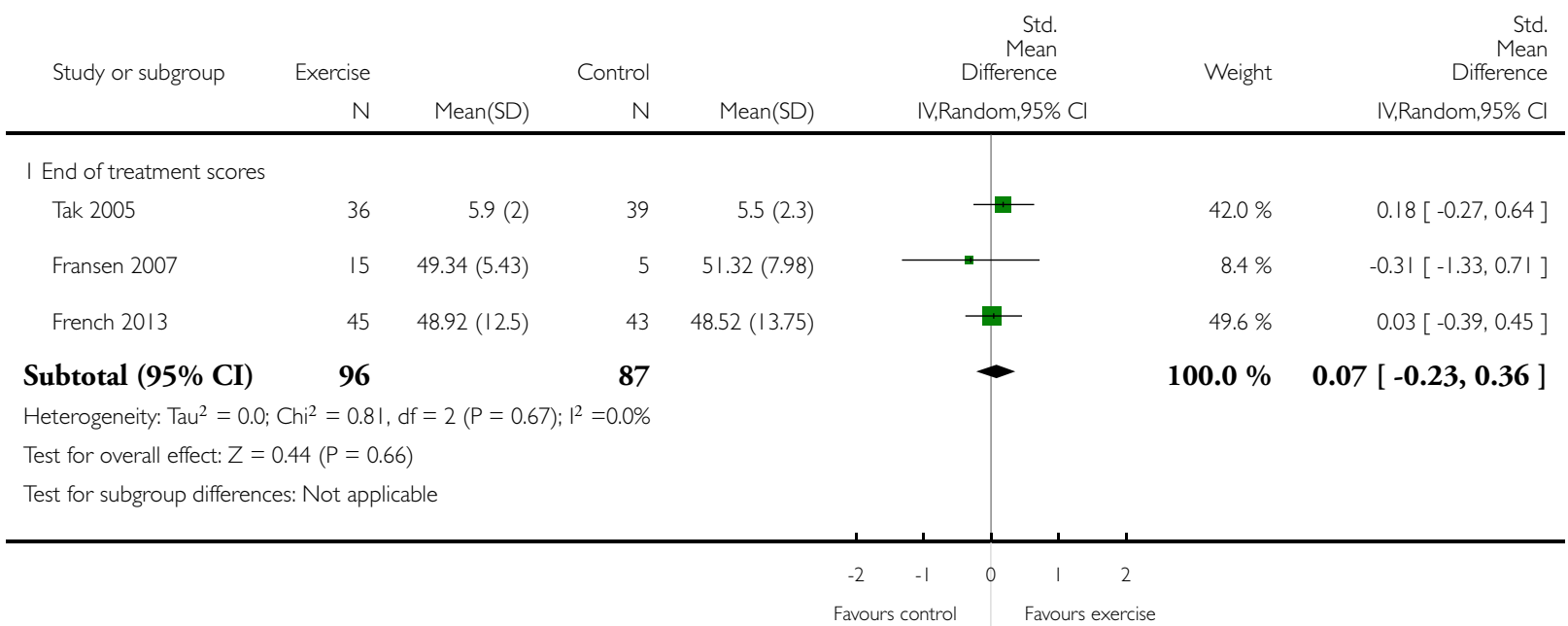




\section{Analysis I.4. Comparison I Immediate post treatment, Outcome 4 Study withdrawals.}

Review: Exercise for osteoarthritis of the hip

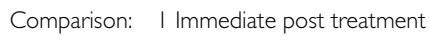

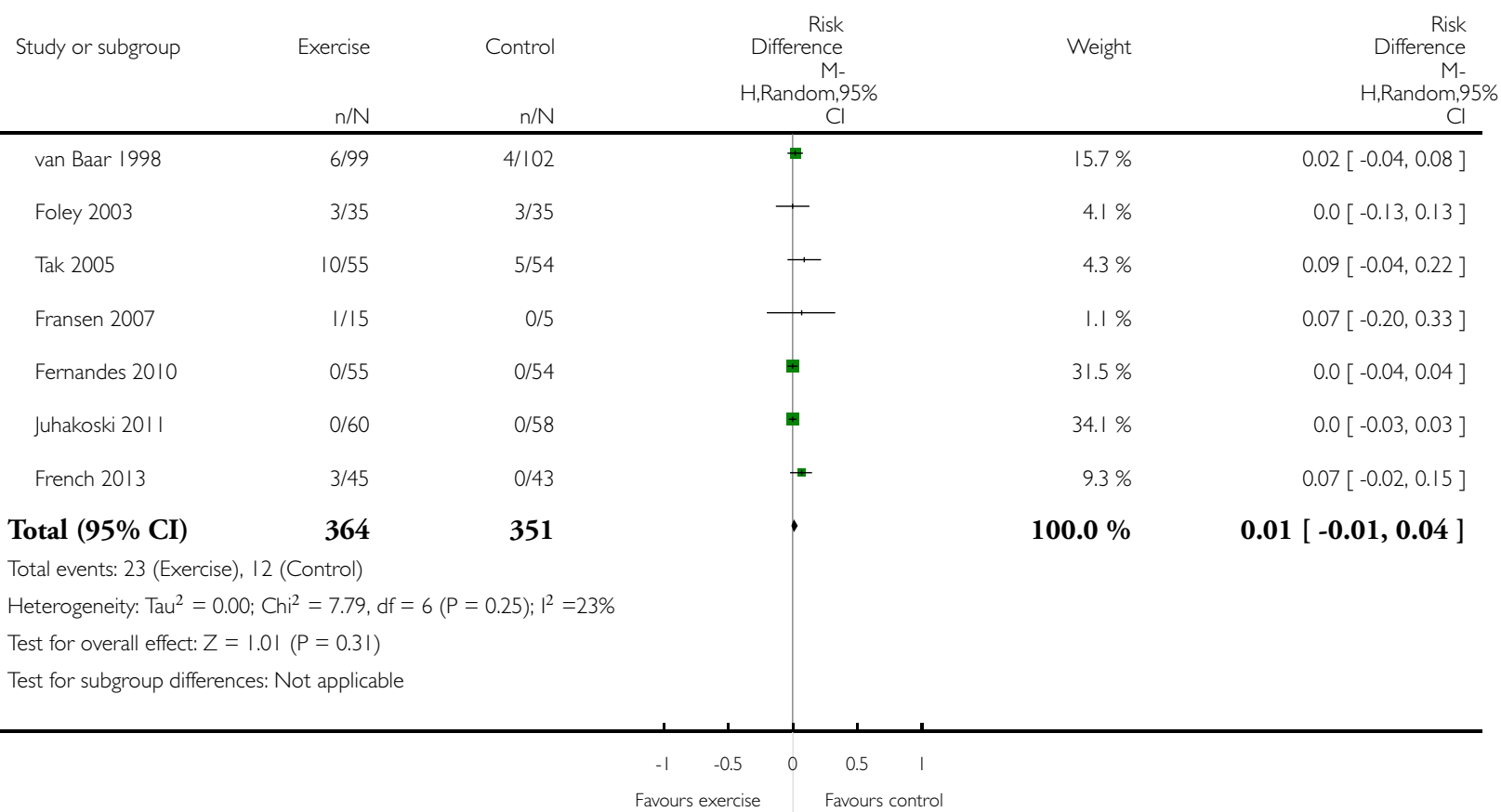




\section{Analysis 2.I. Comparison 2 Sustainability (three to six months), Outcome I Pain.}

Review: Exercise for osteoarthritis of the hip

Comparison: 2 Sustainability (three to six months)

Outcome: I Pain

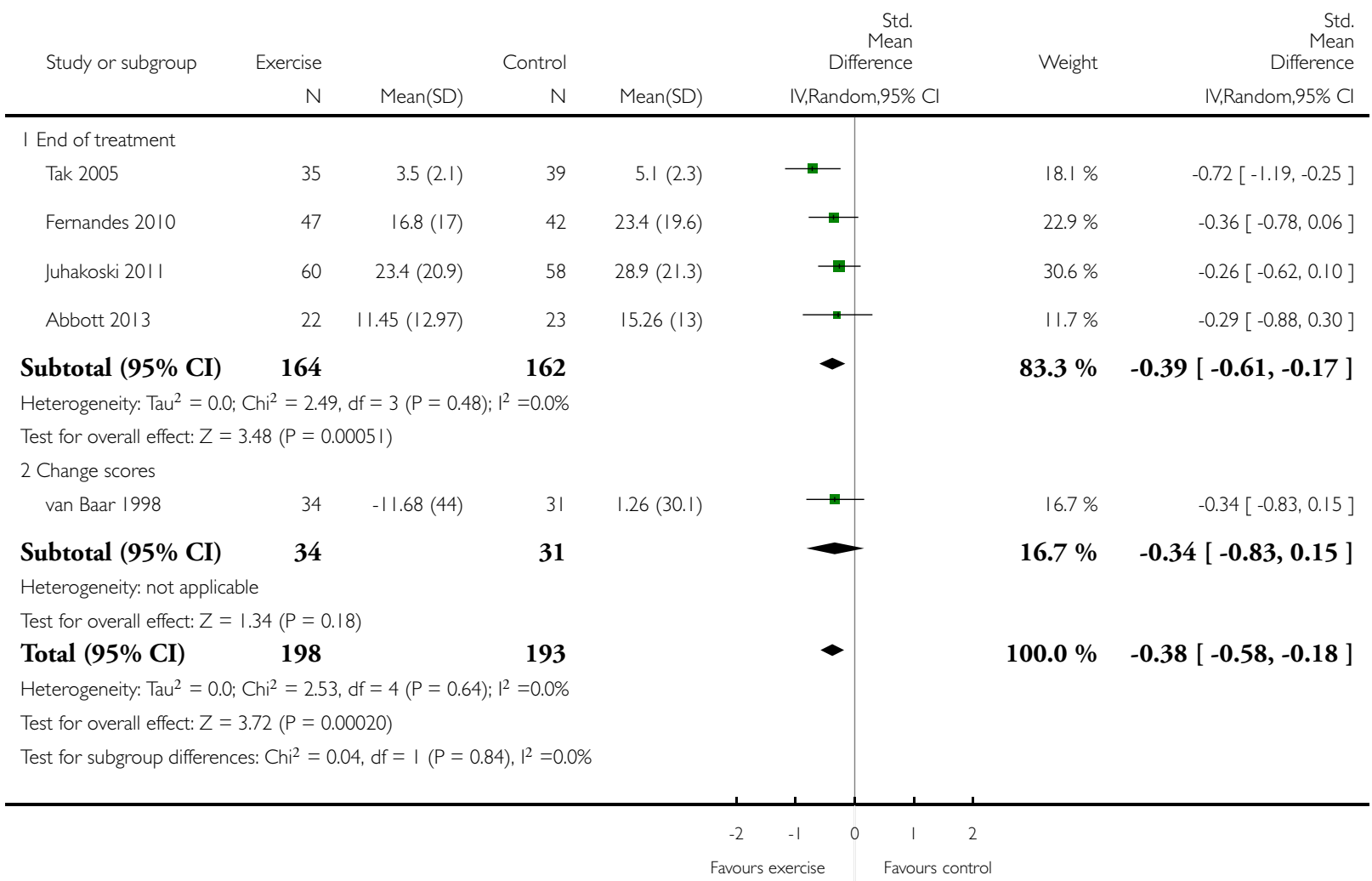


Analysis 2.2. Comparison 2 Sustainability (three to six months), Outcome 2 Physical function.

Review: Exercise for osteoarthritis of the hip

Comparison: 2 Sustainability (three to six months)

Outcome: 2 Physical function

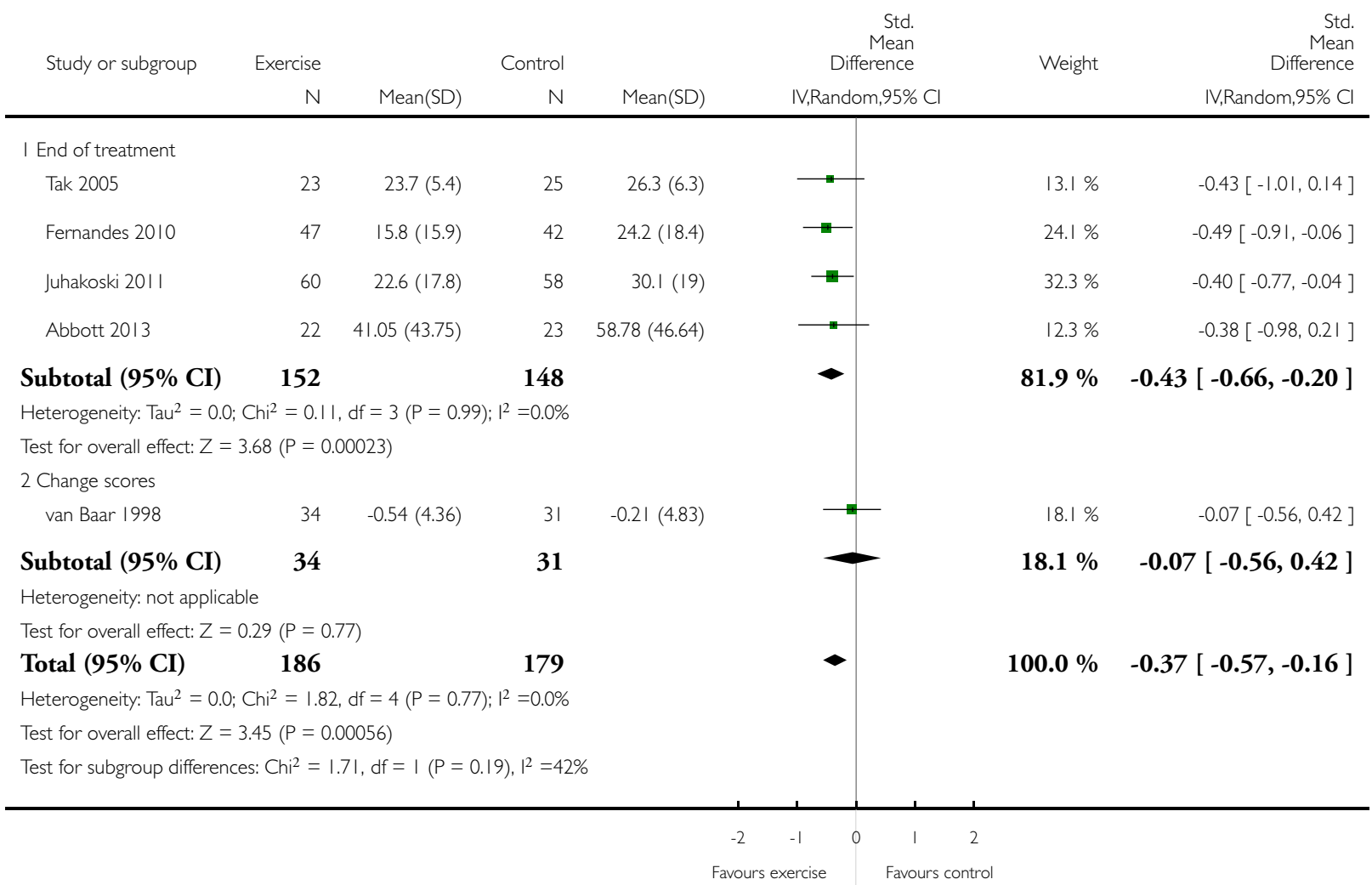


Analysis 3.I. Comparison 3 Hip osteoarthritis (OA) versus hip/knee OA studies, Outcome I Pain post treatment.

Review: Exercise for osteoarthritis of the hip

Comparison: 3 Hip osteoarthritis (OA) versus hip/knee OA studies

Outcome: I Pain post treatment

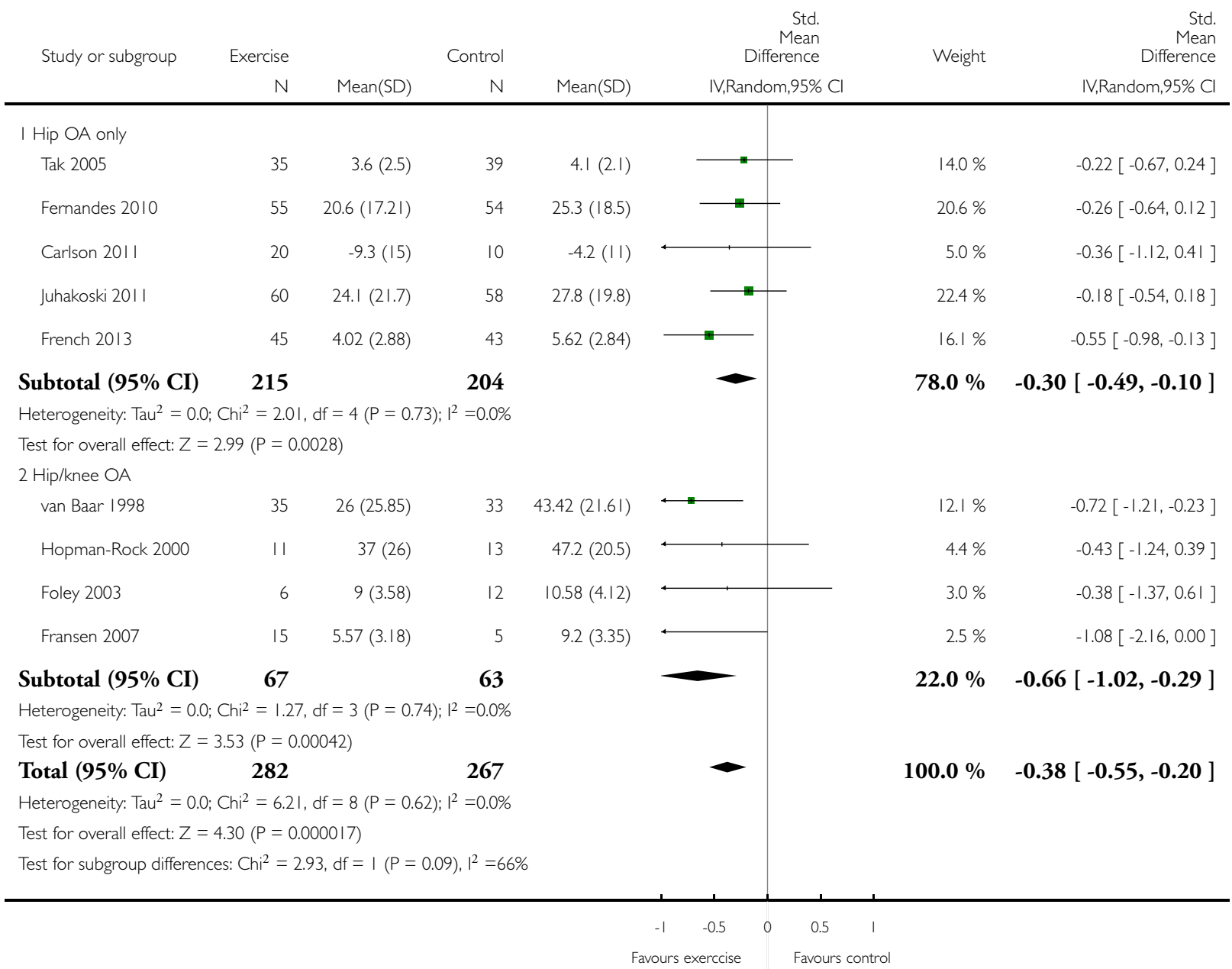


Analysis 3.2. Comparison 3 Hip osteoarthritis (OA) versus hip/knee OA studies, Outcome 2 Physical function post treatment.

Review: Exercise for osteoarthritis of the hip

Comparison: 3 Hip osteoarthritis (OA) versus hip/knee OA studies

Outcome: 2 Physical function post treatment

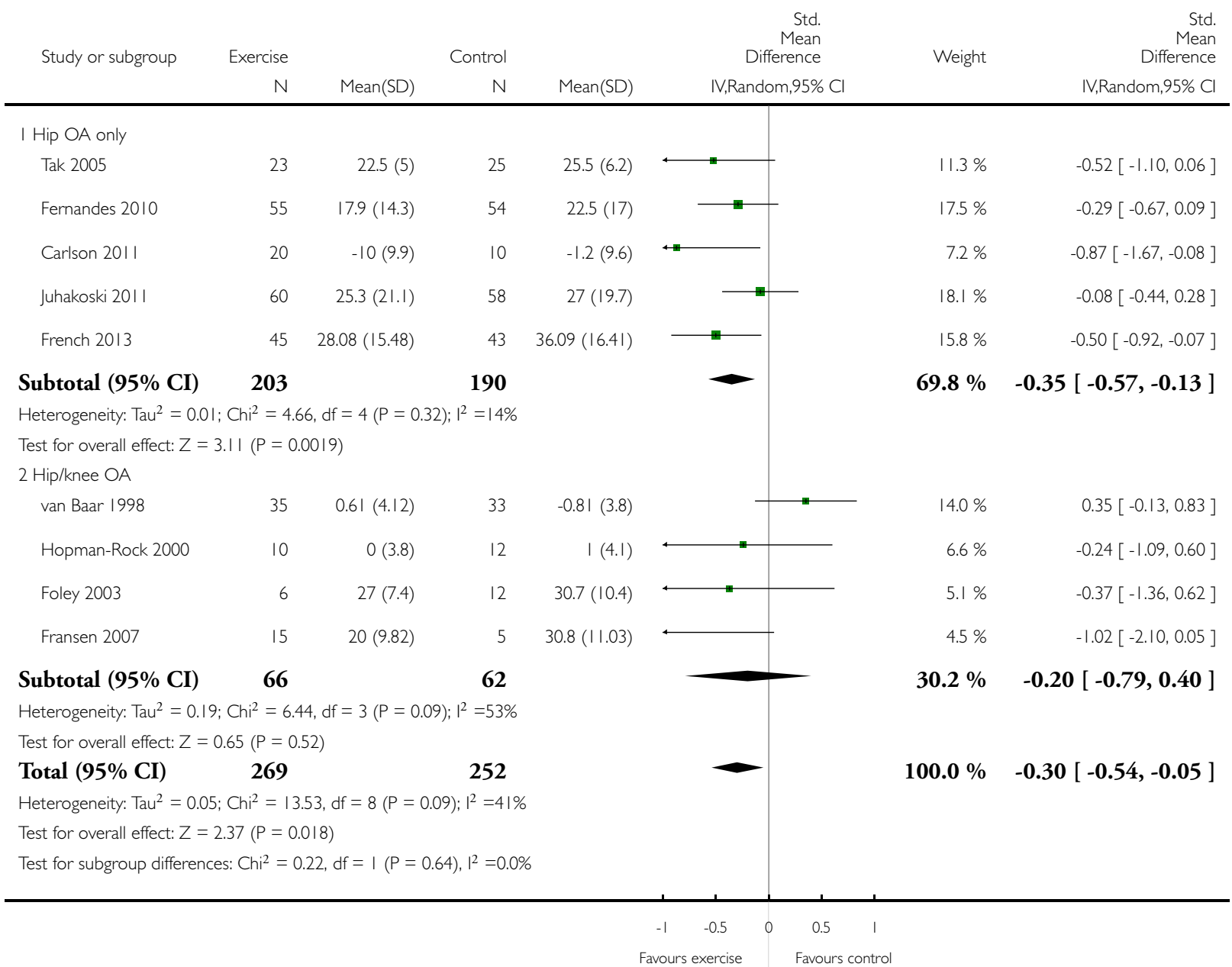




\section{A P P E N D I C ES}

\section{Appendix I. MEDLINE search strategy}

1. exp osteoarthritis/

2. osteoarthr\$.tw.

3. (degenerative adj2 arthritis).tw.

4. arthrosis.tw.

5. or/1-4

6. Hip/

7. exp Hip Joint/

8. hip\$.tw.

9. or/6-8

10. $\exp$ EXERCISE/

11. exp exertion/

12. exp Physical Fitness/

13. exp Exercise Test/

14. exp Exercise Tolerance/

15. exp Sports/

16. exp PLIABILITY/

17. exp Physical Endurance/

18. exertion\$.tw.

19. exercis\$.tw.

20. sport\$.tw.

21. ((physical or motion) adj5 (fitness or therap\$)).tw.

22. (physical\$ adj2 endur\$).tw.

23. ((strength $\$$ or isometric $\$$ or isotonic $\$$ or isokinetic $\$$ or aerobic $\$$ or endurance or weight $\$$ ) adj5 (exercis $\$$ or train $\$)$ ).tw.

24. exp physical therapy modalities/

25. physiotherap\$.tw.

26. manipulat\$.tw.

27. kinesiotherap\$.tw.

28. exp Rehabilitation/

29. rehab\$.tw.

30. (skate $\$$ or skating).tw.

31. run\$.tw.

32. jog\$.tw.

33. treadmill\$.tw.

34. swim\$.tw.

35. bicycl\$.tw.

36. (cycle $\$$ or cycling).tw.

37. walk\$.tw.

38. (row or rows or rowing).tw.

39. muscle strength $\$$.tw.

40. or/10-39

41. randomized controlled trial.pt.

42. controlled clinical trial.pt.

43. randomized.ab.

44. placebo.ab.

45. drug therapy.fs.

46. randomly.ab.

47. trial.ab.

48. groups.ab.

49.41 or 42 or 43 or 44 or 45 or 46 or 47 or 48

Exercise for osteoarthritis of the hip (Review)

Copyright $\odot 2014$ The Cochrane Collaboration. Published by John Wiley \& Sons, Ltd. 
50. humans.sh.

51.49 and 50

52. and $/ 5,9,40,51$

\section{Appendix 2. EMBASE search strategy}

1. exp osteoarthritis/

2. osteoarthr\$.tw.

3. (degenerative adj2 arthritis).tw.

4. arthrosis.tw.

5. or/1-4

6. Hip/

7. hip\$.tw.

8. 6 or 7

9. exp EXERCISE/

10. fitness/

11. exercise test/

12. exercise tolerance/

13. exp Sport/

14. pliability/

15. exp "physical activity, capacity and performance"/

16. exertion $\$$.tw.

17. exercis\$.tw.

18. sport\$.tw.

19. ((physical or motion) adj5 (fitness or therap\$)).tw.

20. (physical\$ adj2 endur\$).tw.

21. ((strength $\$$ or isometric $\$$ or isotonic $\$$ or isokinetic $\$$ or aerobic $\$$ or endurance or weight $\$$ ) adj5 (exercis $\$$ or train $\$)$ ).tw.

22. exp physiotherapy/

23. physiotherap\$.tw.

24. manipulat\$.tw.

25. kinesiotherap\$.tw.

26. exp REHABILITATION/

27. rehab\$.tw.

28. (skate\$ or skating).tw.

29. run\$.tw.

30. jog\$.tw.

31. treadmill\$.tw.

32. swim\$.tw.

33. bicycl\$.tw.

34. (cycle $\$$ or cycling).tw.

35. walk\$.tw.

36. (row or rows or rowing).tw.

37. muscle strength $\$$.tw.

38. or/9-37

39. and $/ 5,8,38$

40. random\$.ti,ab.

41. factorial\$.ti,ab.

42. (crossover\$ or cross over $\$$ or cross-over $\$$ ).ti,ab.

43. placebo $\$ . t i, a b$.

44. (doubl\$ adj blind\$).ti,ab.

45. (singl\$ adj blind\$).ti,ab.

Exercise for osteoarthritis of the hip (Review)

Copyright $\odot 2014$ The Cochrane Collaboration. Published by John Wiley \& Sons, Ltd. 
46. assign\$.ti,ab.

47. allocat\$.ti,ab.

48. volunteer\$.ti,ab.

49. crossover procedure.sh.

50. double blind procedure.sh.

51. randomized controlled trial.sh.

52. single blind procedure.sh.

53. or $/ 40-52$

54. exp animal/ or nonhuman/ or exp animal experiment/

55. exp human/

56.54 and 55

57.54 not 56

58.53 not 57

59.39 and 58

\section{Appendix 3. PEDRO search strategy}

Advanced search

Therapy: Fitness training OR Strength training

Body Part: Thigh or hip

\section{Appendix 4. CINAHL search strategy}

S56 S55 and S42

S55 S54 or S53 or S52 or S51 or S50 or S49 or S48 or S47 or S46 or S45 or S44 or S43 S54 TI Allocat* random* or AB Allocat* random*

S53 (MH "Quantitative Studies")

S52 (MH "Placebos")

S51 TI Placebo* or AB Placebo*

S50 TI Random* allocat* or AB Random* allocat*

S49 (MH "Random Assignment")

S48 TI Randomi?ed control* trial $^{*}$ or AB Randomi?ed control* trial $^{*}$

S47 TI singl* mask* or TI doubl* mask* or TI treb* mask* or TI tripl* mask* or AB singl* mask* or AB doubl* mask* or AB treb* mask* or $\mathrm{AB}$ tripl* mask*

S46 TI singl* blind* or TI doubl* blind* or TI treb* blind* or TI tripl* blind* or AB singl* blind* or AB doubl* blind* or AB treb* blind* or AB tripl* blind*

S45 TI "clinic* trial*" or AB "clinic* trial*”

S44 PT Clinical Trial

S43 (MH "Clinical Trials+")

S42 S41 and S40 and S5

S41 S39 or S38 or S37 or S36 or S35 or S34 or S33 or S32 or S31 or S30 or S29 or S28 or S27 or S26 or S25 or S24 or S23 or S22 or $S 21$ or $S 20$ or $S 19$ or $S 18$ or $S 17$ or $S 16$ or $S 15$ or $S 14$ or $S 13$ or $S 12$ or $S 11$ or $S 10$ or $S 9$ or S8 or S7 or S6

S40 S8 or S7 or S6

S39 (ti “muscle strength*”) or (ab "muscle strength*”)

S38 (ti row or rows or rowing) or (ab row or rows or rowing)

S37 (ti walk*) or (ab walk*)

S36 (ti cycle* or cycling) or (ab cycle* or cycling)

S35 (ti bicycl $\left.{ }^{*}\right)$ or $\left(\right.$ ab bicycl $\left.{ }^{*}\right)$

S34 (ti swim*) or (ab swim*)

S33 (ti swim*) or (ab swim*)

S32 (ti treadmill*) or (ab treadmill*)

Exercise for osteoarthritis of the hip (Review)

Copyright @ 2014 The Cochrane Collaboration. Published by John Wiley \& Sons, Ltd. 
S31 (ti jog*) or (ab jog*)

S30 (ti run*) or (ab run*)

S29 (ti skate* or skating) or (ab skate* or skating)

S28 (ti rehab*) or (ab rehab*)

S27 (MH "Rehabilitation+")

S26 (ti kinesiotherap*) or (ab kinesiotherap*)

S25 (ti manipulat*) or (ab manipulat*)

S24 (ti physiotherap*) or (ab physiotherap*)

S23 (MH "Physical Therapy+")

S22 TI ( strength* or isometric* or isotonic* or isokinetic*or aerobic* or endurance or weight* ) or AB ( strength* or isometric* or isotonic* or isokinetic* or aerobic* or endurance or weight*

S21 TI physical* ${ }^{*} 2$ endur* or $\mathrm{AB}$ physical* $\mathrm{n} 2$ endur*

S20 TI physical N5 fitness or TI physical N5 therap* or AB physical N5 fitness or AB physical N5 therap* or TI motion n5 therap* or $\mathrm{AB}$ motion $\mathrm{n} 5$ therap*

S19 (ti sport*) or (ab sport*)

S18 (ti exercis*) or (ab exercis*)

S17 (ti exertion*) or (ab exertion*)

S16 (MH "Physical Endurance+")

S15 (MH "Pliability

S14 (MH "Sports+")

S13 (MH "Exercise Tolerance+")

S12 (MH "Exercise Test+")

S11 (MH "Physical Fitness")

S10 (MH "Exertion+")

S9 (MH "Exercise+")

S8 (ti hip*) or (ab hip*)

S7 (MH "Hip Joint

S6 (MH "Hip")

$\mathrm{S} 5 \mathrm{~S} 4$ or $\mathrm{S} 3$ or $\mathrm{S} 2$ or $\mathrm{S} 1$

$\mathrm{S} 4$ (ti arthrosis) or (ab arthrosis)

S3 (ti degenerative N2 arthritis) or (ab degenerative N2 arthritis)

S2 (ti osteoarthr*) or (ab osteoarthr*)

S1 (MH “Osteoarthritis+")

\section{Appendix 5. The Cochrane Library search strategy}

MeSH descriptor Osteoarthritis explode all treesosteoarthr*:ti,ab(degenerative next arthritis):ti,abarthrosis:ti,ab(\#1 OR \#2 OR \#3 OR \#4)MeSH descriptor Knee explode all treesMeSH descriptor Knee Joint explode all treesknee*:ti,ab(\#6 OR \#7 OR \#8)MeSH descriptor Exercise explode all treesMeSH descriptor Exertion explode all treesMeSH descriptor Physical Fitness explode all treesMeSH descriptor Exercise Test explode all treesMeSH descriptor Exercise Tolerance explode all treesMeSH descriptor Sports explode all treesMeSH descriptor Pliability explode all treesMeSH descriptor Physical Endurance explode all treesexertion*:ti,abexercis*: ti,absport*:ti,ab((physical or motion) near/5 (fitness or therap*)):ti,ab(physical* near/2 endur*):ti,ab((strength* or isometric* or isotonic* or isokinetic* or aerobic* or endurance or weight*) near/5 (exercis* or train*)):ti,abMeSH descriptor Physical Therapy Modalities explode all trees(physical next therap*):ti,abphysiotherap*:ti,abmanipulat*:ti,abkinesiotherap*:ti,abMeSH descriptor Rehabilitation explode all treesrehab*:ti,ab(skate* or skating):ti,abrun*:ti,abjog*:ti,abtreadmill*:ti,abswim*:ti,abbicycl*:ti,ab(cycle* or cycling): ti,abwalk*:ti,ab(row or rows or rowing):ti,abmuscle next strength:ti,ab(\#10 OR \#11 OR \#12 OR \#13 OR \#14 OR \#15 OR \#16 OR \#17 OR \#18 OR \#19 OR \#20 OR \#21 OR \#22 OR \#23 OR \#24 OR \#25 OR \#26 OR \#27 OR \#28 OR \#29 OR \#30 OR \#31 OR \#32 OR \#33 OR \#34 OR \#35 OR \#36 OR \#37 OR \#38 OR \#39 OR \#40)(\#5 AND \#9 AND \#41)

Exercise for osteoarthritis of the hip (Review) 


\section{WHAT'S NEW}

Last assessed as up-to-date: 9 May 2013.

\begin{tabular}{l|l|l}
\hline Date & Event & Description \\
\hline 24 March 2014 & New citation required and conclusions have changed & $\begin{array}{l}\text { Change in conclusions on update: significant benefit in } \\
\text { terms of physical function now demonstrated } \\
\text { Methods were updated in accordance with current } \\
\text { Cochrane Collaboration recommendations: risk of bias as- } \\
\text { sessment and Summary of Findings Tables added } \\
\text { Quality of life assessment and study withdrawal rates were } \\
\text { added in the update } \\
\text { Pain and physical function outcomes were further disag- } \\
\text { gregated into immediate post treatment effects and sus- } \\
\end{array}$ \\
& &
\end{tabular}

9 May $2013 \quad$ New search has been performed

Five new studies added to this update: Fernandes 2010; Juhakoski 2011; Carlson 2011; French 2013; Abbott 2013

\section{H I S T O R Y}

Review first published: Issue 3, 2009

\begin{tabular}{l|l|l}
\hline Date & Event & Description \\
\hline 19 April 2009 & New citation required but conclusions have not changed & Substantive amendment \\
\hline 14 January 2009 & New search has been performed & $\begin{array}{l}\text { This updated review is one of two Cochrane reviews } \\
\text { replacing an earlier review, 'Exercise for osteoarthritis of } \\
\text { the hip or knee'. Since the original review, the editors } \\
\text { decided to subdivide the review into separate conditions. }\end{array}$ \\
\hline 14 January 2009 & Amended & $\begin{array}{l}\text { The Background section has been revised to provide in- } \\
\text { formation on the specific disorder only, and the search } \\
\text { strategy has been revised accordingly. The Methods sec- } \\
\text { tion has been updated to reflect current Cochrane Mus- } \\
\text { culoskeletal Group methods. }\end{array}$ \\
\hline & & $\begin{array}{l}3 \text { new studies were added in this updated review: Foley } \\
\text { 2003; Fransen 2007; Tak 2005 }\end{array}$ \\
\hline
\end{tabular}




\section{CONTRIBUTIONSOFAUTHORS}

Three review authors (SM, MF, GH) independently screened retrieved clinical studies for inclusion, extracted data from all included studies and conducted the methodological quality assessment. If we did not reach an agreement at any stage, a fourth review author (SR) adjudicated. All four review authors reviewed the final manuscript prior to submission.

\section{DECLARATIONSOF INTEREST}

None.

\section{SOURCES OF SUPPORT}

\section{Internal sources}

- S Reichenbach is funded by the Swiss National Science Foundation's National Research Program 53 on musculoskeletal health (grant no. 4053-40-104762), and the Mäxi Foundation, Switzerland.

\section{External sources}

- No sources of support supplied

\section{DIFFERENCES BETWEEN PROTOCOLANDREVIEW}

We have updated the methods in the review since the original protocol, in accordance with the current recommended methods of the Cochrane Musculoskeletal Group, and The Cochrane Collaboration. The original protocol was for a review entitled "Exercise for osteoarthritis of the hip or knee". Since the original review, the editors decided to subdivide the review into two reviews of separate conditions. For this update of the specific review for hip OA, we have added two more outcomes: quality of life and study withdrawal rates. We have also now conducted a sensitivity analysis according to recruitment criteria, comparing studies recruiting only participants with hip OA with those recruiting participants with hip or knee OA.

\section{NDEX TERMS}

\section{Medical Subject Headings (MeSH)}

*Exercise Therapy; *Hip Joint; Arthralgia [*therapy]; Osteoarthritis, Hip [ ${ }^{*}$ therapy]; Randomized Controlled Trials as Topic

\section{MeSH check words}

Humans 